Esta revista forma parte del acervo de la Biblioteca Jurídica Virtual del Instituto de Investigaciones Jurídicas de la UNAM

\title{
El cambio de nombre conforme a la identidad de género en Costa Rica: una revisión a la luz del derecho internacional de los derechos humanos
}

\author{
Name Change According to Gender Identity \\ in Costa Rica: a Review of Compatibility with \\ International Human Rights Law
}

\section{Changement de nom selon l'identité de genre au Costa Rica: un examen de la compatibilité avec le droit international des droits de l'homme}

\author{
Jorge Arturo Ulloa Cordero* \\ Víctor Alonso Vargas Sibaja**
}

\begin{abstract}
SUMARIO: I. Introducción. II. El derecho a la identidad de género protege el cambio de nombre. III. Derecho al cambio de nombre conforme a la identidad de género. IV. Estándares internacionales sobre el procedimiento de cambio de nombre. V. Sobre la adecuación del artículo 54 del Código Civil costarricense a los estándares internacionales. VI. Conclusiones generales.

VII. Bibliografía.
\end{abstract}

* Licenciado en derecho por la Universidad de Costa Rica. Actualmente cursa una maestría en sociología jurídico-penal en la Universidad de Barcelona.

** Bachiller en derecho con honores por la Universidad de Costa Rica y egresado de la licenciatura en derecho de la misma institución universitaria. Pasante de la Corte Penal Internacional.

Esta investigación, con algunas modificaciones, fue presentada por los autores ante la honorable Corte Interamericana de Derechos Humanos a modo de amicus curiae en la solicitud de Opinión Consultiva presentada por el Estado de Costa Rica el 18 de mayo de 2016.

Artículo recibido el 7 de marzo de 2017 Aprobado para publicación el 25 de septiembre de 2017 
RESUMEN: El presente artículo realiza una revisión de los estándares en el derecho internacional de los derechos humanos, tanto de aspectos sustantivos como de procedimiento, respecto del reconocimiento legal del cambio de nombre de las personas conforme a su identidad de género. Posteriormente, se realiza un análisis de la incompatibilidad de las normas del ordenamiento jurídico costarricense con dichos estándares. Y, finalmente, se realiza una propuesta de interpretación conforme de la normativa costarricense a estos estándares internacionales.

Palabras clave: derecho al nombre, derecho a la identidad personal, cambio de nombre, identidad de género.

ABSTRACT: This article makes an exhaustive review of the standards set out by International Human Rights Law, both in substantive and procedural law, regarding the legal recognition of name change according to each person's gender identity. Moreover, it proves the incompatibility of Costa Rican law provisions with these international standards. Finally, this article proposes a conforming interpretation of the Costa Rican law to tackle these difficulties.

Key words: right to name, right to personal identity, name change, gender identity.

RÉSUMÉ: Cet article fait un examen exhaustif des normes énoncées par le droit international des droits de l'homme, en ce qui concerne le droit positif et le droit procédural, à l'égard de de la reconnaissance juridique du changement de nom selon l'identité de genre de chaque individu. Par ailleurs, l'incompatibilité du droit costaricien avec ces normes internationales est prouvée. En dernier lieu, cet article propose une interprétation conforme de la loi costaricienne pour traiter ces difficultés.

Mots-clés: droit de nommer, droit à l'identité personnelle, changement de nom, identité de genre. 
Esta revista forma parte del acervo de la Biblioteca Jurídica Virtual del Instituto de Investigaciones Jurídicas de la UNAM

\section{INTRODUCCIÓN}

El desarrollo en el derecho internacional de los derechos humanos de la identidad de género como categoría protegida es reciente. La atención que ha recibido por parte de los Estados a nivel internacional es escasa, ${ }^{1}$ y todavía enfrenta importantes barreras políticas para su progresivo reconocimiento. En el sistema interamericano de derechos humanos, dicho reconocimiento se dio a partir del caso Atala Riffo y niñas vs. Chile ${ }^{2}$ de la Corte Interamericana de Derechos Humanos (en adelante, Corte IDH).

Como parte de los ingentes esfuerzos para implementar los estándares a nivel interno de los Estados, Costa Rica presentó el 18 de mayo de 2016 una solicitud de Opinión Consultiva ante la Corte IDH, para que, inter alia, resolviera la siguiente consulta: "la protección que brindan los artículos 11.2, 18 y 24 en relación con el artículo 1 de la [Convención Americana de Derechos Humanos] $]^{3}$ al reconocimiento del cambio de nombre de las personas, de acuerdo con la identidad de género de cada una"; y "la compatibilidad de la práctica que consiste en aplicar el artículo 54 del Código Civil de la República de Costa Rica, Ley no. 63 del 28 de setiembre de 1887, a las personas que deseen optar por un cambio de nombre a partir de su identidad de género, con los artículos 11.2, 18 y 24, en relación con el artículo 1 de la Convención". ${ }^{4}$

En este estudio se demostrará que la $\mathrm{CADH}$ protege el cambio de nombre conforme a la identidad de género de las personas y que la legislación de Costa Rica es incompatible con esta protección. Con este propósito se establecerá que tanto a) el derecho a la identidad de género como b) la prohibición de la discriminación y el derecho al nombre protegen el cambio de este último conforme a la identidad de género. Posteriormente, se analizarán c) los estándares internacionales sobre el procedimiento de cambio de nom-

1 Baisley, Elizabeth, "Reaching the Tipping Point? Emerging International Human Rights Norms Pertaining to Sexual Orientation and Gender Identity”, Human Rights Quarterly, Estados Unidos, vol. 38, núm. 1, febrero de 2016, p. 135.

2 Corte Interamericana de Derechos Humanos, Caso Atala Riffo y niñas vs. Chile, Fondo, reparaciones y costas. Sentencia del 24 de febrero de 2012, Serie C 239, párr. 91.

3 En adelante, CADH.

4 Opinión Consultiva del Estado de Costa Rica, 18 de mayo de 2016, pp. 1 y 2. 
Esta revista forma parte del acervo de la Biblioteca Jurídica Virtual del Instituto de Investigaciones Jurídicas de la UNAM

bre. Conforme a las demostraciones hechas, se harán consideraciones sobre d) la adecuación del artículo 54 del Código Civil costarricense con los estándares internacionales en la materia. Finalmente, se formularán conclusiones generales con recomendaciones para adecuar la normativa costarricense a los estándares del derecho internacional de los derechos humanos.

\section{EL DERECHO A LA IDENTIDAD DE GÉNERO PROTEGE EL CAMBIO DE NOMBRE}

\section{Sexo y género: breves precisiones conceptuales}

Antes de abordar el derecho a la identidad de género, es menester hacer una breve precisión conceptual de los conceptos "sexo" y "género".

Por mucho tiempo, los términos "sexo" y "género" se usaron indistintamente como sinónimos. Fue hasta la segunda mitad del siglo XX cuando los feministas acuñaron el término "género" con las connotaciones actuales y como una categoría distinta a la de "sexo". ${ }^{5}$ Actualmente existen varias definiciones de una y otra categoría.

El Comisario de Derechos Humanos del Consejo de Europa manifestó en un informe que el término "sexo" alude a las diferencias biológicas entre hombres y mujeres, mientras que "género" incluye el aspecto social de la diferencia entre los géneros en adición al elemento biológico. ${ }^{6}$ Por su parte la Comisión Interamericana de Derechos Humanos entiende "sexo" como:

[Una] construcción social en la literatura académica queer e intersex... Esta idea trasciende el concepto de sexo como masculino o femenino, y como un fenómeno biológico. Bajo esta teoría, la asignación del sexo no es un hecho biológico innato; más bien, a las personas se les asigna socialmente un sexo al nacer con base en la percepción que otras personas tienen sobre sus genitales. Aunque en la mayoría de los casos las personas son fácilmente clasificadas como niño o niña, algunas pre-

5 Gauché, Ximena, "Derecho, derechos humanos y diversidad sexual" en Erazo, Ximena et al. (eds.), Derechos humanos, diversidad sexual y políticas públicas en América Latina, Chile, LOM Ediciones-Fundación Henry Dunant, 2015, p. 42.

6 Hammaberg, Thomas, Derechos humanos e identidad de género, Berlín, TransInterQueer e.V., 2010, p. 5. 
Esta revista forma parte del acervo de la Biblioteca Jurídica Virtual del Instituto de Investigaciones Jurídicas de la UNAM

sentaciones del cuerpo son percibidas como "ambiguas", y el proceso de asignación sexual no es inmediato. ${ }^{7}$

En relación con el binario "sexo" y "género", la Comisión considera que son modelos sociales que abarcan categorías rígidas de hombre/masculino y mujer/femenino que excluyen abiertamente a grupos como los transexuales. ${ }^{8}$

No obstante, el criterio que se seguirá a lo largo de este artículo será el definido por el Comisario de Derechos Humanos del Consejo de Europa, por ser éste el compatible con la terminología utilizada en las fuentes citadas infra.

Ahora bien, los términos "sexo" y "género" mantienen una relación importante, sobre todo cuando se trata de definir la identidad de género. En este sentido, cabe señalar que la Comisión Interamericana de Derechos Humanos ha puntualizado que normativamente, a nivel del sistema interamericano, se presupone una cisnormatividad, es decir, la expectativa de que las personas desarrollarán su identidad de género conforme al sexo asignado al nacer. ${ }^{9}$ Cuando una persona cumple con tales parámetros se le denomina "cisgénero". ${ }^{10}$

Por ende, la cisnormatividad ha supuesto que, como bien indica Amnistía Internacional en la mayoría de legislaciones, el género legalmente asignado al nacer corresponde siempre con el sexo. En caso de que una persona cuente con una identidad de género que no corresponda con esta condición biológica, debe activar los mecanismos para lograr el reconocimiento legal de esta circunstancia. ${ }^{11}$

Es precisamente esta cisnormatividad la que motivó la consulta del Estado de Costa Rica, dado que su ordenamiento jurídico, al igual que la mayoría de los países del sistema interamericano, ${ }^{12}$ construye su legislación a partir de una cisnormatividad. Lo anterior implica, por ejemplo, que las normas relativas a la asignación del nombre y género de la persona

7 Comisión Interamericana de Derechos Humanos, Violencia contra personas lesbianas, gay, bisexuales, trans e intersex en América, Organización de los Estados Americanos, 2015, párr. 16.

8 Ibidem, párr. 34.

9 Ibidem, párr. 32.

10 Ibidem, párr. 32.

11 Amnistía Internacional, El Estado decide quién soy. Falta de reconocimiento legal de la identidad de género de las personas transgénero en Europa, 2014, p. 5. En el mismo sentido, véase Hammaberg, Thomas, op. cit., p. 5.

12 Comisión Interamericana de Derechos Humanos, op. cit., párr. 48. 
Esta revista forma parte del acervo de la Biblioteca Jurídica Virtual del Instituto de Investigaciones Jurídicas de la UNAM

en Costa Rica supongan una adecuación con el sexo asignado al nacer. La interrelación de los conceptos "sexo" y "género", como se entiende modernamente, permite acuñar el derecho a la identidad de género, conforme se analiza a continuación.

\section{Concepto y naturaleza jurídica del derecho a la identidad de género}

Se considera que los términos "orientación sexual" e "identidad de género" son más inclusivos que la enunciación propia de una categoría de identidades específicas como gay, lesbiana, trans, entre otros. ${ }^{13}$ De esta manera, para lograr un enfoque lo más inclusivo posible se hará únicamente referencia a "identidad de género". ${ }^{14}$

El concepto más aceptado de "identidad de género" se encuentra en el preámbulo de los Principios de Yogyakarta sobre la aplicación de la legislación internacional de derechos humanos en relación con la orientación sexual y la identidad de género, el cual la entiende como:

[L]a vivencia interna e individual del género tal como cada persona la siente profundamente, la cual podría corresponder o no con el sexo asignado al momento del nacimiento, incluyendo la vivencia personal del cuerpo (que podría involucrar la modificación de la apariencia o la función corporal a través de medios médicos, quirúrgicos o de otra índole, siempre que la misma sea libremente escogida) y otras expresiones de género, incluyendo la vestimenta, el modo de hablar y los modales. ${ }^{15}$

13 O’Flaherty, Michael y Fisher, John, “Sexual Orientation, Gender Identity and International Human Rights Law: Contextualising the Yogyakarta Principles”, Human Rights Law Review, vol. 8, núm. 2, 2008, p. 247.

14 No obstante, en los casos en los que la jurisprudencia o doctrina utilice el concepto “trans”, no se cambiará para respetar la fuente.

15 Principios de Yogyakarta sobre la aplicación de la legislación internacional de derechos humanos en relación con la orientación sexual y la identidad de género, Panel Internacional de Especialistas en Legislación Internacional de Derechos Humanos y en Orientación Sexual e Identidad de Género, marzo de 2007, disponible en: http: / /www.refworld.org/cgi-bin/ texis $/ v t x /$ rwmain $/$ opendocpdf.pdf?reldoc $=y \& d o c i d=48244 e 9 f 2$. Cfr. Hamzić, Vanja, "The Case of «Queer Muslims»: Sexual Orientation and Gender Identity in International Human Rights Law and Muslim Legal and Social Ethos”, Human Rights Law Review, vol. 11, núm. 2, 2011, p. 240; Gauché, Ximena, op. cit., p. 43. 
Esta revista forma parte del acervo de la Biblioteca Jurídica Virtual del Instituto de Investigaciones Jurídicas de la UNAM

Si bien los Principios de Yogyakarta constituyen el soft law, no por ello carecen de efectos jurídicos en el derecho internacional. ${ }^{16}$ Por su naturaleza complementan instrumentos del hard law directamente aplicables al sistema interamericano. ${ }^{17}$ La propia Corte IDH ha aplicado estos Principios en su jurisprudencia. ${ }^{18}$ Asimismo, la doctrina les ha otorgado un peso considerable en el análisis de la identidad de género en el derecho internacional de los derechos humanos. ${ }^{19}$

En línea con esta tendencia se tomarán dichos Principios para la interpretación de diversos puntos relativos a la identidad de género en el derecho internacional de los derechos humanos.

Han sido recientes y escasas las instancias en las que se ha reconocido la identidad de género como un derecho humano. En el sistema universal, la positivización de la identidad de género se ha dado principalmente en el contexto de la normativa antidiscriminación. Sin embargo, ha sido poca la atención que ha recibido la identidad de género en el plano internacional. ${ }^{20}$

No fue hasta el 2009 que el Comité de Derechos Económicos Sociales y Culturales de la Organización de las Naciones Unidas aprobó por primera vez un comentario general sobre no discriminación en el que se reconoció el derecho a la identidad de género. ${ }^{21}$ En varias oportunidades, tanto en el Consejo de Derechos Humanos como en la Asamblea General, ambos de la ONU, diversos Estados se han manifestado sobre las crecientes violaciones a los derechos humanos basadas en la orientación sexual y en la identidad de género. ${ }^{22}$

16 Shaw, Malcolm, International Law, 5a. ed., Reino Unido, Cambridge University Press, 2003, pp. 110 y 111; Del Toro Huerta, Mauricio Iván, "El fenómeno del soft law y las nuevas perspectivas del derecho internacional", Anuario Mexicano de Derecho Internacional, vol. 6, 2006, disponible en: https: / / revistas.juridicas.unam.mx/index.php/derecho-internacional/article/view/160/257\#N50.

17 Del Toro Huerta, Mauricio Iván, op. cit.

18 Corte Interamericana de Derechos Humanos, Caso Duque vs. Colombia, Excepciones preliminares, Fondo, reparaciones y costas. Sentencia del 26 de febrero de 2016, Serie C 310, párr. 110 .

19 Cfr. Hamzić, Vanja, op. cit., p. 240; Gauché, Ximena, op. cit., p. 43.

20 Baisley, Elizabeth, op. cit., p. 135; O’Flaherty, Michael y Fisher, John, op. cit., pp. 227 y 228. Hamzić, Vanja, op. cit., p. 242.

21 Hamzić, Vanja, op. cit., pp. 244-251.

22 Hamzić, Vanja, op. cit., pp. 244 y 245. Del Consejo de Derechos Humanos véanse, inter alia, las siguientes resoluciones: Resolución A/HRC/RES/17/19, Consejo de Derechos Humanos, 14 de julio de 2011, disponible en: https://documents-dds-ny.un.org/doc/ 
Esta revista forma parte del acervo de la Biblioteca Jurídica Virtual del Instituto de Investigaciones Jurídicas de la UNAM

En el sistema europeo, el primer instrumento del hard law en recoger la identidad de género como motivo prohibido de discriminación fue el Convenio del Consejo de Europa sobre prevención y lucha contra la violencia contra las mujeres y la violencia doméstica de $2011 .{ }^{23}$ El artículo 4.3 de esta Convención establece "La aplicación por las Partes de las disposiciones del presente Convenio... sin discriminación alguna, basada en... la identidad de género". ${ }^{24}$

Por su parte, el Tribunal Europeo de Derechos Humanos (en lo sucesivo, TEDH) ha tenido la oportunidad de analizar la identidad de género en diversos asuntos sometidos a su conocimiento. La doctrina emanada de este Tribunal se considera como pionera y la más desarrollada en materia de derecho internacional de derechos humanos en relación con la orientación sexual y la identidad de género. ${ }^{25}$

Estos criterios, como se verá, han sido interpretados de manera más progresiva hasta estos días. En un inicio, el TEDH no consideraba que el Convenio Europeo de Derechos Humanos confiriese protección alguna a la identidad de género. Así, en los casos Rees vs. Reino Unido y Cossey vs. Reino Unido, elTEDH resolvió que el Reino Unido no estaba obligado a modificar los certificados de nacimiento de los demandantes para reflejar el cambio producto de una cirugía de reasignación de sexo. ${ }^{26}$ Lo anterior por cuanto quedaba comprendido en el margen de apreciación de los Estados reconocer legalmente el cambio de sexo. ${ }^{27}$ Doce años después, en el caso Sheffield y Horsham vs. Reino Unido, el TEDH adoptó el mismo enfoque conservador. ${ }^{28}$

UNDOC/GEN/G11/148/76/PDF/G1114876.pdf?OpenElement (fecha de consulta: 1 de febrero de 2017), y Resolución A/HRC/RES/32/2, Consejo de Derechos Humanos, 15 de julio de 2016, disponible en: http://www.un.org/en/ga/search/view_doc.asp?symbol=A/HRC/ RES/32/2_(fecha de consulta: 1 de febrero de 2017).

23 McGoldrick, Dominic, "The Development and Status of Sexual Orientation Discrimination under International Human Rights Law”, Human Rights Law Review, vol. 16, núm. 4, 2016, p. 633.

24 Convenio del Consejo de Europa sobre prevención y lucha contra la violencia contra las mujeres y la violencia doméstica, 11 de mayo de 2011, disponible en: https: / / rm.coe.int/CoERMPublic CommonSearchServices / DisplayDCTMContent? documentId =0900001680462543 (fecha de consulta: 20 de enero de 2017.

25 Hamzić, Vanja, op. cit., p. 243.

26 Hogg, Martin, "Attitudes to Sexual Identity and Practice: The Impact of Human Rights Law in the Scottish Courts”, en Boyle, Alan et al. (eds.), Human Rights and Scots Law, Oxford y Oregon, Hart Publishing, 2002, p. 226.

27 Ibidem, pp. 226 y 227.

28 Ibidem, p. 227. 
Esta revista forma parte del acervo de la Biblioteca Jurídica Virtual del Instituto de Investigaciones Jurídicas de la UNAM

Sin embargo, en el caso B vs. Francia, el TEDH — cuyo pronunciamiento se dio inclusive antes de emitirse el fallo de Sheffield y Horsham vs. Reino Unidorealizó un tímido reconocimiento del derecho a la identidad de género. En $B$ vs. Francia, el Tribunal declaró que no permitir el cambio de nombre conforme a la identidad de género es una violación al artículo 8o. del Convenio Europeo de Derechos Humanos que tutela el derecho a la vida privada. ${ }^{29}$ No obstante, atemperó esta afirmación al señalar que el caso $B$ se distingue de los casos Rees y Cossey, pues en el primero se discutía la negativa de Francia de modificar los documentos de estado civil, no de los certificados de nacimiento como ocurrió en los segundos. ${ }^{30}$

No fue sino hasta el 2002 que el TEDH, en los casos Christine Goodwin vs. Reino Unido e I vs. Reino Unido, reconoció por primera vez el derecho a la identidad de género como derecho humano. ${ }^{31} \mathrm{Si}$ bien este derecho no se encuentra textualmente incorporado en el Convenio Europeo, el TEDH, mediante una interpretación de este instrumento, lo estimó incorporado.

Para realizar su análisis, el TEDH se ha referido al artículo 8 del Convenio Europeo de Derechos Humanos el cual señala: “Artículo 8. Derecho al respeto a la vida privada y familiar. 1 . Toda persona tiene derecho al respeto de su vida privada y familiar, de su domicilio y de su correspondencia". ${ }^{32} \mathrm{Se}$ gún ha interpretado ese Tribunal, la protección del artículo 8o. del Convenio implica una obligación negativa por parte de los Estados de no interferir y una obligación positiva de tomar medidas para protegerlo. ${ }^{33}$

Asimismo, ha concluido que ese numeral tutela la autonomía personal y, con ello, el derecho a establecer detalles de la identidad como ser humano individual. ${ }^{34}$ Por lo anterior, el concepto de autonomía personal tutelado

29 Tribunal Europeo de Derechos Humanos, Caso B vs. Francia. Sentencia del 25 de marzo de 1992, Solicitud número 13343/87, párr. 58.

30 Hogg, Martin, op. cit., p. 227.

31 Theilen, Jens, "Depathologisation of Transgenderism and International Human Rights Law”, Human Rights Law Review, vol. 14, núm. 2, 2014, p. 328. Hamzić, Vanja, op. cit., pp. 248 y 249 .

32 Convenio Europeo de Derechos Humanos, Consejo de Europa, 4 de noviembre de 1950, artículo 8o., disponible en: http://www.echr.coe.int/documents/convention_spa.pdf.

33 Rudolf, Beate, "European Court of Human Rights: Legal status of postoperative transsexuals", International Journal of Constitutional Law, vol. 1, núm. 4, 2003, p. 717.

34 Ibidem, p. 719. 
Esta revista forma parte del acervo de la Biblioteca Jurídica Virtual del Instituto de Investigaciones Jurídicas de la UNAM

engloba el derecho a establecer la identidad propia. ${ }^{35}$ Por su relación con el derecho anterior, el TEDH ha estimado que el principio de la autonomía personal es una derivación de la dignidad humana. ${ }^{36}$

Ahora bien, este derecho a establecer una identidad incluye, entre otros, el derecho a elegir una orientación sexual y una identidad de género, ya que ambos presuponen el derecho a la vida privada. ${ }^{37}$ Asimismo, el TEDH ha indicado que el derecho a escoger una identidad de género es uno de los aspectos esenciales de la autodeterminación. ${ }^{38}$

En consecuencia, la falta de reconocimiento legal del cambio de género es una violación hacia el derecho al respeto de la vida privada, tutelado en el artículo 8o. del Convenio Europeo. ${ }^{39}$ En el caso L vs. Lituania, el TEDH inclusive llegó a equiparar el derecho a la identidad de género con el derecho a establecer la verdadera identidad propia (one's true identity). ${ }^{40}$

En suma, elTEDH ha establecido que el derecho a la identidad de género es una derivación del artículo 8o. del Convenio Europeo de Derechos Humanos que tutela el derecho a la vida privada. Sin embargo, la afirmación de este derecho autónomo no ha ocurrido aún en el sistema interamericano.

En el sistema interamericano, la Organización de los Estados Americanos (en lo sucesivo OEA) ha reconocido desde 2007 el derecho a la diversidad sexual y de género. ${ }^{41}$ Declaraciones posteriores en $2008,{ }^{42}$

35 Tribunal Europeo de Derechos Humanos, Caso Christine Goodwin vs. Reino Unido. Sentencia del 11 de julio de 2002, Solicitud número 28957/95, párrs. 85 y 90; Tribunal Europeo de Derechos Humanos, Caso I. vs. Reino Unido. Sentencia del 11 de julio de 2002, Solicitud número 25680/94, párrs. 65 y 70; Rudolf, Beate, op. cit., p. 717.

36 Rudolf, Beate, op. cit., p. 719.

37 Grigolo, Michele, "Sexualities and the ECHR: Introducing the Universal Sexual Legal Subject”, European Journal of International Law, vol. 14, núm.5, 2003, pp. 1039 y 1040.

38 O’Flaherty, Michael y Fisher, John, op. cit., pp. 220 y 221.

39 Tribunal Europeo de Derechos Humanos, Sección Cuarta, Caso Grant vs. Reino Unido. Sentencia del 23 de mayo de 2006, Solicitud número 32570/03, párr. 40; Tribunal Europeo de Derechos Humanos, Caso Christine Goodwin..., cit., párr. 93; Hammaberg, Thomas, op. cit., p. 11.

40 Hamzić, Vanja, op. cit., pp. 248 y 249.

41 Ibidem, p. 247.

42 Resolución AG/RES. 2435 (XXXVIII-O/08), Asamblea General de la OEA, 3 de junio de 2008, disponible en: http://www.oas.org/es/sla/ddi/docs/AG-RES_2435_XXXVIII-O-08.pdf (fecha de consulta: 14 de enero de 2017). 
Esta revista forma parte del acervo de la Biblioteca Jurídica Virtual del Instituto de Investigaciones Jurídicas de la UNAM

$2009,{ }^{43} 2010,{ }^{44} 2011,{ }^{45} 2012^{46}$ y $2013^{47}$ han manifestado la preocupación de la OEA por violaciones a los derechos humanos basadas en la orientación sexual y en la identidad de género.

En sede contenciosa, en el mismo sistema regional de derechos humanos, la Corte IDH ha tenido la oportunidad de pronunciarse sobre la identidad de género en los casos Atala Riffo y niñas vs. Chile y Duque vs. Colombia. Una breve referencia también fue realizada en el caso Flor Freire vs. Ecuador.

En el caso Atala Riffo y Niñas vs. Chile, manifestó que la identidad de género es una categoría protegida bajo el artículo 1.1 de la CADH. Por lo tanto "ninguna norma, decisión o práctica de derecho interno, sea por parte de autoridades estatales o por particulares, pueden disminuir o restringir, de modo alguno, los derechos de una persona". ${ }^{48}$ Inmediatamente hace saber ese alto tribunal que la falta de consenso al interior de los países no es un argumento válido para discriminar en razón de identidad de género. ${ }^{49}$ Tratándose de la restricción de un derecho, la prohibición de discriminación por identidad de género invierte la carga de la prueba y exige que el Estado haga una fundamentación rigurosa y demuestre que su decisión no tenía un propósito ni un efecto discriminatorio. ${ }^{50}$

Otro punto de relevancia en la Sentencia de comentario es lo relativo al derecho a la vida privada. Según ese Tribunal, el artículo 11 de la CADH

43 Resolución AG/RES. 2504 (XXXIX-O/09), Asamblea General de la OEA, 4 de junio de 2009, disponible en: http://www.oas.org/es/sla/ddi/docs/AG-RES_2504_XXXIX-O-09.pdf (fecha de consulta: 14 de enero de 2017).

44 Resolución AG/RES. 2600 (XL-O/10), Asamblea General de la OEA, 8 de junio de 2010, disponible en: http://www.oas.org/es/sla/ddi/docs/AG-RES_2600_XL-O-10_esp.pdf(fecha de consulta: 14 de enero de 2017).

45 Resolución AG/RES. 2653 (XLI-0/11), Asamblea General de la OEA, 7 de junio de 2011, disponible en: http://www.oas.org/es/sla/ddi/docs/AG-RES_2653_XLI-O-11_esp.pdf (fecha de consulta: 14 de enero de 2017).

46 Resolución AG/RES. 2721 (XLII-O/12), Asamblea General de la OEA, 4 de junio de 2012, disponible en: http://www.oas.org/es/sla/ddi/docs/AG-RES_2721_XLII-O-12_esp.pdf (fecha de consulta: 14 de enero de 2017).

47 Resolución AG/RES. 2807 (XLIII-O/13), Asamblea General de la OEA, 6 de junio de 2013, disponible en: http://www.oas.org/es/sla/ddi/docs/AG-RES_2807_XLIII-O-13.pdf_(fecha de consulta: 14 de enero de 2017).

48 Corte Interamericana de Derechos Humanos, Caso Atala Riffo..., cit., párr. 91.

49 Ibidem, párr. 92.

50 Ibidem, párr. 124. 
Esta revista forma parte del acervo de la Biblioteca Jurídica Virtual del Instituto de Investigaciones Jurídicas de la UNAM

protege la vida privada, la cual incluye "la vida sexual y el derecho a establecer y desarrollar relaciones con otros seres humanos... incluye la forma en que el individuo se ve a sí mismo y cómo y cuándo decide proyectar a los demás". ${ }^{51}$ Dentro de esta categoría, ese Tribunal citó la orientación sexual. ${ }^{52}$

En el caso Duque vs. Colombia, esta Corte reiteró que la identidad de género es una categoría protegida por el artículo 1.1 de la $\mathrm{CADH}$, por lo que se encuentra proscrita cualquier restricción o negación de derechos con fundamento en la identidad de género. ${ }^{53}$ En caso de un trato diferenciado por motivo de identidad de género, el Estado está obligado a ofrecer una justificación objetiva y razonable, y sus decisiones deben estar sustentadas en una argumentación exhaustiva. ${ }^{54}$ Finalmente recalcó que la falta de consenso al interior de los países no es un argumento válido para discriminar en razón de identidad de género. ${ }^{55}$

Por último, en el caso Flor Freire vs. Ecuador, el Tribunal interamericano reiteró el reconocimiento internacional de la prohibición de actos de violencia y discriminación por identidad de género. ${ }^{56}$

Así, la jurisprudencia de la Corte IDH ha reconocido únicamente la identidad de género como motivo prohibido de discriminación. Igualmente, la Corte ha abogado por una interpretación amplia del término "vida privada”, sin precisar inequívocamente que en éste cabe la categoría de identidad de género. Esta concepción amplia de vida privada no encuentra respaldo unánime a nivel doctrinal, toda vez que algunos autores advierten que el ámbito de protección de este derecho es vago e impreciso. ${ }^{57}$ Sin embargo, la Corte IDH no podría adoptar una concepción restringida so pena de

51 Ibidem, párrs. 162 y 163.

52 Ibidem, párr. 163.

53 Corte Interamericana de Derechos Humanos, Caso Duque..., cit., párr. 104.

54 Ibidem, párr. 106.

55 Ibidem, párr. 123.

56 Corte Interamericana de Derechos Humanos, Caso Flor Freire vs. Ecuador, Excepción preliminar, Fondo, reparaciones y costas. Sentencia del 31 de agosto de 2016, Serie C 315, párrs. 122 y 123.

57 Cfr. Jingchun, Cao, "Protecting the Right to Privacy in China", Victoria University of Wellington Law Review, vol. 36, núm. 3, 2005, disponible en: https://www.victoria.ac.nz/law/re search/publications/vuwlr/prev-issues/vol-36-3/jingchun.pdf; Solove, Daniel, "Conceptualizing Privacy”, California Law Review, vol. 90, núm. 4, 2002, disponible en: http: //scholarship.law. berkeley.edu /cgi / viewcontent.cgi?article $=1408$ \&context $=$ californialawreview . 
Esta revista forma parte del acervo de la Biblioteca Jurídica Virtual del Instituto de Investigaciones Jurídicas de la UNAM

adoptar un enfoque regresivo de su jurisprudencia. En aras de mantener la consistencia con sus precedentes y de un enfoque pro homine, la Corte debería reconocer mediante una interpretación evolutiva de la CADH que el derecho a la identidad de género es un derecho en sí mismo derivable del artículo 11 de dicho tratado.

La interpretación evolutiva que han desarrollado la Corte IDH y elTEDH sostiene que los tratados de derechos humanos son instrumentos vivos que deben interpretarse conforme a la evolución de los tiempos y a las condiciones de vida actuales. ${ }^{58}$ Asimismo, esta interpretación corresponde a un método necesario en los instrumentos de derechos humanos con el fin de actualizar el contenido de las garantías reconocidas en ellos y que éstas sean prácticas y efectivas. ${ }^{59}$ De ahí que sea necesario que la Corte IDH acuda a la interpretación evolutiva cada vez que examine la $\mathrm{CADH}$.

Mediante esta interpretación evolutiva, la Corte IDH tiene la facultad de dar una interpretación más amplia al derecho a la vida privada, protegido en el artículo 11 de la CADH. Para estos efectos puede acudir a tres métodos: a) acudir a la jurisprudencia del TEDH, $b$ ) el creciente consenso entre los Estados de la región y c) recurrir a su propia jurisprudencia.

En cuanto al primer método, aun cuando la jurisprudencia del TEDH no es directamente aplicable al sistema interamericano, ${ }^{60}$ las sentencias emanadas de ese Tribunal pueden asistir a la Corte IDH en su labor interpretativa de la Convención, tal y como ha sido la práctica constante del tribunal interamericano. ${ }^{61}$ Ahora bien, el TEDH al analizar el artículo 8o. del Convenio Europeo de Derechos Humanos, que en su literalidad es muy similar al numeral 11 de la CADH, concluyó que la vida privada incluye la identidad de género. Asimismo, al interpretar el término "respeto" del Convenio Europeo, cuyo significado es análogo al de "no interferencia", contenido en el tratado interamericano, concluyó que se imponen obligaciones tanto positivas como negativas a los Estados.

58 Corte Interamericana de Derechos Humanos, Caso Atala Riffo..., cit., párr. 83.

59 Cárdenas Velásquez, Byron Guadalupe, El control de las normas internas en la jurisprudencia del Tribunal Europeo de Derechos Humanos y la Corte Interamericana de Derechos Humanos: especial consideración del caso de España y Nicaragua, tesis doctoral, Barcelona, Universidad Autónoma de Barcelona, 2015, pp.100 y 101.

60 Estatuto de la Corte Internacional de Justicia, artículo 38; Shaw, Malcolm, op. cit., p. 103.

61 Cárdenas Velásquez, Byron Guadalupe, op. cit., pp.100 y 101. 
Esta revista forma parte del acervo de la Biblioteca Jurídica Virtual del Instituto de Investigaciones Jurídicas de la UNAM

Otro método al cual puede acudir la Corte IDH para facilitar una interpretación evolutiva de la Convención es el creciente consenso de los Estados en la región. Hay países que han ido reconociendo progresivamente derechos relativos a la identidad de género; en Colombia, es posible realizar el cambio de nombre y de sexo en una sede administrativa. ${ }^{62}$ La Corte Constitucional de ese país ha estimado que todos los derechos de las personas trans se derivan del principio de autonomía.$^{63}$ En particular, ha estipulado que las personas trans tienen derecho al libre desarrollo de la personalidad - por ejemplo, realizar un cambio de nombre concordante con su identidad de género- - a la expresión de la individualidad, a la identidad, a la libre opción sexual y a la identidad sexual. ${ }^{64}$ Propiamente, en torno al derecho a la identidad sexual, ha establecido que:

[L]a dignidad es la fuente del derecho a la identidad sexual, entendida como la autonomía y autoridad propia de cada persona, orientada a fines específicos en ejercicio de su libertad, esto en otras palabras es asumir al individuo como dueño de su propio ser, ya que "la persona por su misma plenitud, es dueña de sí, es el sujeto autónomo y libre. En otros términos, el distintivo de ser persona y el fundamento de la dignidad de la persona es el dominio de lo que quiere ser" ${ }^{65}$

En Argentina, la Ley 26.743 de 2012 establece el derecho de toda persona al reconocimiento de su identidad de género, al libre desarrollo de su persona conforme a su identidad de género y a ser tratada y reconocida conforme a la misma en los documentos que registran su nombre de pila, imagen y sexo. ${ }^{66}$

62 Decreto 1227, Ministerio de Justicia y el Derecho de la República de Colombia, 4 de junio de 2015, disponible en: https://www.minjusticia.gov.co/Portals/0/Ministerio/decreto\%20 unico /\%23\%20decretos / 1.\%20DECRETO\%202015-1227\%20sexo\%20cédula.pdf (fecha de consulta: 20 de enero de 2017).

63 Espinosa Pérez, Beatriz, “Cuerpos e identidades. El transexualismo reta al derecho”, en Espinosa Pérez, Beatriz (ed.), Cuerpos y diversidad sexual: aportes para la igualdad y el reconocimiento, Bogotá, Pontificia Universidad Javeriana, 2008, p. 75.

64 Ibidem, pp. 75-77.

65 Corte Constitucional de Colombia, Sala Sexta de Revisión, BB vs. Notaría Primera del Círculo de Bogotá y la Registraduría Distrital del Estado Civil, Expediente T-5.196.402. Sentencia del 22 de febrero de 2016, sección 3.3.1.

66 Ley núm. 26.743, Senado y Cámara de Diputados de la Nación Argentina, 9 de mayo de 2012, disponible en: http://www.tgeu.org/sites/default/files/ley_26743.pdf (fecha de consulta: 25 de enero de 2017). 
Esta revista forma parte del acervo de la Biblioteca Jurídica Virtual del Instituto de Investigaciones Jurídicas de la UNAM

Asimismo, en Ecuador, la Ley Orgánica de Gestión de la Identidad y Datos Civiles permite la captura de fotografías para la cédula de identidad y realizar el cambio de sexo conforme a la identidad de género de las personas. ${ }^{67}$

En Bolivia, la Ley de Identidad de Género permite el cambio de nombre, sexo e imagen en toda documentación pública y privada vinculada a la identidad de la persona. ${ }^{68}$

En Uruguay, la Ley 18.620, relativa al derecho a la identidad de género y al cambio de nombre y sexo en documentos identificatorios, reconoce "la identidad de género propia y la consonancia entre esta identidad y el nombre y sexo señalado en los documentos identificatorios de la persona" ${ }^{69}$ Para realizar la adecuación de los documentos de identificación a esta nueva circunstancia, el interesado debe incoar un procedimiento judicial. ${ }^{70}$

En Perú, desde 2016, el cambio de nombre y de sexo se debe realizar por la vía judicial, según lo dispuso el Tribunal Constitucional de ese país. ${ }^{71}$ Desde el 15 de diciembre del año anterior se tramita en la corriente legislativa un proyecto de Ley de Identidad de Género. ${ }^{72}$

En la Ciudad de México, es posible realizar dichos cambios con sólo incoar un procedimiento administrativo. ${ }^{73}$

67 Ley núm. 40, Ley Orgánica de Gestión de la Identidad y Datos Civiles, Asamblea Nacional de la República del Ecuador, 4 de febrero de 2016, disponible en: http://www.asam bleanacional.gob.ec/es/system/files/ro_ley_organica_de_gestion_de_la_identidad_y_datos_ci viles_ro_684_2do_supl_04-02-2015.pdf (fecha de consulta: 20 de enero de 2017).

68 Ley núm. 807, Ley de Identidad de Género, Asamblea Legislativa Plurinacional del Estado Plurinacional de Bolivia, 21 de mayo de 2016, disponible en: http: / /www.derechoteca.com / gacetabolivia/ley-no-807-del-21-de-mayo-de-2016 (fecha de consulta: 20 de enero de 2017).

69 Ley núm. 18620, Ley de derecho a la identidad de género y al cambio de nombre y sexo en documentos identificatorios, Senado y Cámara de Representantes de la República Oriental del Uruguay, 25 de octubre de 2009, art. 1, disponible en: https://legislativo.parlamento. gub.uy/temporales/leytemp4059060.htm_(fecha de consulta: 20 de enero de 2017).

70 Ibidem, art. 4.

71 Tribunal Constitucional del Perú, Recurso de agravio constitucional interpuesto por Rodolfo Enrique Romero Saldarriaga (Ana Romero Saldarriaga), Sentencia del 21 de octubre de 2016, Exp. STC 06040-2015-PA/TC, párr. 17, disponible en: http://www.tc.gob.pe/juris prudencia/2016/06040-2015-AA.pdf.

72 Disponible en: http: / / www.congreso.gob.pe/proyectosdeley.

73 Código Civil para el Distrito Federal, Asamblea Legislativa del Distrito Federal, 5 de febrero de 2015, artículos 135 bis, ter y quáter, disponible en: http: / /www.aldf.gob.mx/archivoc9dc6843e50163a0d2628615e069b140.pdf (fecha de consulta: 20 de enero de 2017). 
Esta revista forma parte del acervo de la Biblioteca Jurídica Virtual del Instituto de Investigaciones Jurídicas de la UNAM

Por último, en Canadá, en lugares como Columbia Británica ${ }^{74}$ y Manitoba, ${ }^{75}$ es posible el cambio de los mismos mediante la interposición de un procedimiento administrativo.

Finalmente, la Corte IDH puede echar mano de su propia jurisprudencia para facilitar esta interpretación evolutiva. En el caso Atala Riffo y niñas vs. Chile, el Tribunal dispuso que la vida privada incluye la forma en la que el individuo se ve a sí mismo y cómo y cuándo decide proyectar a los demás. ${ }^{76}$ Esta concepción amplia de la vida privada engloba precisamente el derecho a la identidad de género, ya que éste permite al sujeto decidir cómo se proyecta a terceros y a sí mismo.

\section{Reconocimiento legal de la identidad de género}

El eventual reconocimiento por parte de la Corte IDH del derecho a una identidad de género como parte de la vida privada lleva consigo una serie de implicaciones. Para ello, nuevamente, puede acudir a una interpretación evolutiva conforme a los parámetros del TEDH y a otros estándares internacionales.

El derecho a la identidad de género alude a las obligaciones estatales que surgen bajo el derecho a la vida privada en el contexto del reconocimiento de género. ${ }^{77}$ Estas obligaciones no se limitan a un no hacer por parte de los Estados en el sentido de no interferir arbitrariamente, sino de tomar medidas para proteger este derecho. ${ }^{78}$ Un simple no hacer implicaría únicamente tolerar, no tutelar efectivamente este derecho y le negaría todo reconocimiento público. ${ }^{79}$

Como lo ha indicado el TEDH, la discordancia entre la posición asumida socialmente por la persona trans y el estatus impuesto legalmente que se niega a reconocer el cambio de género no puede ser vista como un inconve-

74 Vital Statistics Act, 29 de mayo de 2014, Columbia Británica, Canadá, disponible en: http://canlii.ca/t/5297t (fecha de consulta: 21 de enero de 2017).

75 Vital Statistics Act, 10 de noviembre de 2016, Manitoba, Canadá, disponible en: http: / / canlii.ca/t/52tvp_(fecha de consulta: 21 de enero de 2017).

76 Corte Interamericana de Derechos Humanos. Caso Atala Riffo..., cit., párrs. 162 y 163.

77 Theilen, Jens, op. cit., 330.

78 Rudolf, Beate, op. cit., p. 717.

79 Grigolo, Michele, op. cit., p. 1040. 
Esta revista forma parte del acervo de la Biblioteca Jurídica Virtual del Instituto de Investigaciones Jurídicas de la UNAM

niente de poca importancia, es una seria interferencia a la vida privada. Este conflicto entre la realidad social y la legal genera sentimientos de vulnerabilidad, humillación y ansiedad. ${ }^{80}$

Por lo anterior, los Estados están obligados a reconocer legalmente el cambio de sexo y permitir, entre otros derechos, la rectificación de la información relativa al estado civil y las consecuencias que de ello se deriven. ${ }^{81}$ Las modificaciones que se deban ejecutar en asientos del registro civil no son un argumento en contra del reconocimiento legal de la identidad de género. ${ }^{82}$ Entre estos cambios se encuentra el de nombre, ${ }^{83}$ objeto de la consulta presentada por el Estado de Costa Rica. Por ende, el reconocimiento legal de la identidad de género tiene como corolario el acreditar el cambio de nombre conforme a esta identidad.

\section{DERECHO AL CAMBIO DE NOMBRE} CONFORME A LA IDENTIDAD DE GÉNERO

Como quedó establecido, el derecho a la identidad de género tiene como corolario el reconocimiento del cambio de nombre conforme a la identidad de género de cada persona. No obstante, consideramos que una interpretación armónica de la prohibición de discriminación (artículo 1.1 de la Convención Americana) ${ }^{84}$ con el derecho al nombre (artículo 18 de la Convención Americana) ${ }^{85}$ también protege el cambio de nombre señalado.

80 Tribunal Europeo de Derechos Humanos. Caso Christine Goodwin ..., cit., párr. 77.

81 Tribunal Europeo de Derechos Humanos, Gran Cámara, Caso Hamalainan vs. Finlandia. Sentencia del 16 de julio de 2014, Solicitud número 37359/09, párr. 68.

82 Tribunal Europeo de Derechos Humanos. Caso Christine Goodwin..., cit., párrs. 87 y 88.

83 Recomendación 1117/1989, Parliamentary Assembly of Council of Europe, 29 de septiembre de 1989, disponible en: http://assembly.coe.int/nw/xml/XRef/Xref-XML2HTML-en. asp?fileid=15151 \&lang=en (fecha de consulta: 1 de febrero de 2017).

84 De conformidad con la interpretación de "otra condición social" que realizó la Corte IDH en las sentencias Atala Riffo y niñas vs Chile y Duque vs Colombia, supra citadas.

85 Dicho artículo prescribe: "Artículo 18. Derecho al nombre. Toda persona tiene derecho a un nombre propio y a los apellidos de sus padres o al de uno de ellos. La ley reglamentará la forma de asegurar este derecho para todos, mediante nombres supuestos, si fuere necesario". 
Esta revista forma parte del acervo de la Biblioteca Jurídica Virtual del Instituto de Investigaciones Jurídicas de la UNAM http://www.juridicas.unam.mx/ https://biblio.juridicas.unam.mx/bjv https://revistas.juridicas.unam.mx/ DOI: http://dx.doi.org/10.22201/iij.24487872e.2018.18.12102

La Corte IDH ha declarado que la identidad de género es una categoría prohibida de discriminación al tenor de la Convención Americana. ${ }^{86}$ Esta cláusula impide restringir o negar un derecho con base en esta condición. ${ }^{87}$ El derecho al nombre, por su parte, está protegido por el artículo 18 de la $\mathrm{CADH}, \mathrm{y}$ con respecto a éste el alto tribunal ha establecido:

Igualmente, los Estados deben garantizar que la persona sea registrada con el nombre elegido por ella o por sus padres, según sea el momento del registro, sin ningún tipo de restricción al derecho ni interferencia en la decisión de escoger el nombre... El nombre y los apellidos son esenciales para establecer formalmente el vínculo existente entre los diferentes miembros de la familia con la sociedad y con el Estado. ${ }^{88}$

En consecuencia, el derecho al nombre no puede ser negado ni restringido, en especial si el motivo para ello es la identidad de género.

\section{ESTÁNDARES INTERNACIONALES}

SOBRE EL PROCEDIMIENTO DE CAMBIO DE NOMBRE

De acuerdo con lo expuesto, se tiene total certeza de que la población con identidad de género diversa, perteneciente al colectivo conocido como LGBTI, es un sector protegido, de acuerdo con los más altos estándares de derechos humanos. En tal supuesto, el principio de no discriminación (artículos 1.1 y 24 de la CADH) actúa como principio rector que le ordena a los Estados adecuar sus conductas para no generar ningún tipo de situación discriminatoria en contra de dicha población. ${ }^{89}$

86 Corte Interamericana de Derechos Humanos, Caso Atala Riffo..., cit., párr. 91, y caso Duque..., cit., párr. 104.

87 Corte Interamericana de Derechos Humanos, Caso Atala Riffo..., cit., párr. 91.

88 Corte Interamericana de Derechos Humanos, Caso las niñas Yean y Bosico vs. República Dominicana. Sentencia del 8 de setiembre de 2005, Serie C 130, párr. 184, y Caso Personas dominicanas y haitianas expulsadas vs. República Dominicana, Excepciones preliminares, Fondo, reparaciones y costas. Sentencia del 28 de agosto de 2014, Serie C 282, párr. 268.

89 Cfr. Corte Interamericana de Derechos Humanos, Caso Flor..., cit., párr. 111, y Caso Duque vs. ..., cit., párr. 92. 
Esta revista forma parte del acervo de la Biblioteca Jurídica Virtual del Instituto de Investigaciones Jurídicas de la UNAM

En igual sentido, de acuerdo con el derecho de protección a la honra y dignidad de las personas (artículo 11 de la CADH), los Estados no deben permitir ningún tipo de injerencia arbitraria o abusiva en la vida privada de los individuos. Los incumplimientos de estos parámetros de actuación estatal - sea por agentes públicos o privados, en cuanto a la connivencia estatalconlleva un estado de incumplimiento del orden público interamericano, por ser violatorio de una norma del ius cogens. ${ }^{90}$

Lo anterior no sólo implica acciones en sentido negativo de los Estados, como bien ha sido determinado por los organismos de protección de los derechos humanos, sino que éstos deben realizar acciones positivas, ${ }^{91}$ siempre tomando en cuenta la adecuación de los ordenamientos jurídicos internos con los estándares de respeto a los derechos humanos, de acuerdo con el artículo 2o. de la CADH. ${ }^{92}$

Ahora bien - tanto por técnica de escritura como por imposibilidad material - las disposiciones convencionales se han redactado de una forma general y abstracta, por lo que corresponde a los operadores jurídicos, especialmente a aquellos con la autoridad interpretativa, realizar operaciones intelectivas hermenéuticas del texto convencional y adecuar su contenido — sin que implique alteración alguna - con los estándares contemporáneos de derechos humanos. Por ello, debe echarse mano de las pautas esbozadas en la doctrina más especializada a nivel internacional en cuanto al procedimiento que debe existir en los Estados para el cambio de nombre de las personas de acuerdo con su identidad de género.

En primer lugar, los Principios de Yogyakarta ${ }^{93}$ establecen que el derecho al reconocimiento de la personalidad jurídica de las personas con identidad de género diversa estriba en que a éstas se les reconozca el derecho a identificarse de acuerdo con su autodeterminación, su dignidad y su libertad (principio 3). Por lo anterior se exhorta a los Estados a que adopten las medidas legislativas y administrativas para que los documentos identificatorios sean acordes con la identidad de género de las personas, de acuerdo a como éstas se han autodefinido (recomendación C); asimismo, los Estados deben procurar que dichos cambios sean reconocidos en todos los contextos en

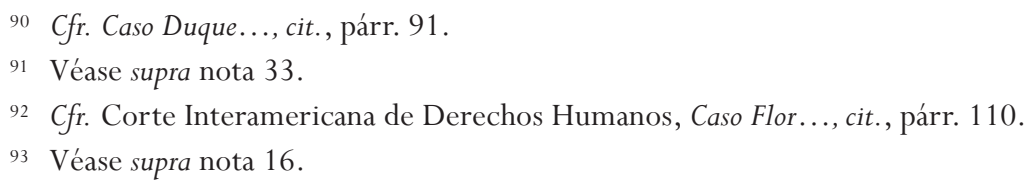


Esta revista forma parte del acervo de la Biblioteca Jurídica Virtual del Instituto de Investigaciones Jurídicas de la UNAM

los cuales las personas se desenvuelven, principalmente cuando sea necesaria la desagregación por sexo (recomendación E).

A nivel europeo, el Comisionado sobre Derechos Humanos de la Unión Europea presentó en el 2009 un informe denominado "Human Rights and Gender Identity", en el cual expuso que el acceso a procedimientos para poder cambiar de nombre y de sexo es esencial para estas personas, pues incide en la mayoría de sus documentos oficiales, como identificaciones, carné de asegurados y certificados educativos. Mencionó, además, que lo tardado de los procedimientos afecta considerablemente a estas personas, por cuanto se les dificulta, inter alia, el acceso al trabajo y poder viajar.

En todo caso, dicho Comisionado expone que los procedimientos que son tardados o, peor, que requieren de procedimientos médicos o dictámenes psiquiátricos previos son contrarios a la garantía de no discriminación de este grupo protegido. Estos procedimientos excesivamente tardados y engorrosos producen que las personas con identidad de género diversa se encuentren marginadas de la sociedad por largos periodos de sus vidas y no se les permite - indirectamente - insertarse a plenitud en el desenvolvimiento social. Se recomienda que los Estados desarrollen procedimientos expeditos y transparentes para el cambio de nombre de acuerdo con la identidad de género, así como eliminar cualquier tipo de examen físico o psiquiátrico para tales menesteres. ${ }^{94}$

En esta misma línea, el Consejo de Derechos Humanos, en su 19o. periodo de sesiones, en el informe del Alto Comisionado de las Naciones Unidas para los Derechos Humanos, intitulado "Leyes y prácticas discriminatorias y actos de violencia cometidos contra personas por su orientación sexual e identidad de género", concluye que el que las personas trans no obtengan el reconocimiento legal de su identidad de género correcta trae consecuencias prácticas y dificultan, inter alia, la obtención de créditos, vivienda y visas para viajar al extranjero. ${ }^{95}$ Por lo anterior, recomendó que los Estados

94 Commissioner for Human Rights, "Human Rights and Gender Identity", Estrasburgo, 2009, pp. 7 y 8, disponible en: https://rm.coe.int/CoERMPublicCommonSearchServices/Display DCTM Content?documentId=09000016806da753 (fecha de consulta: 10 de febrero de 2017.

95 Consejo de Derechos Humanos, Informe del Alto Comisionado de las Naciones Unidas para los Derechos Humanos, "Leyes y prácticas discriminatorias y actos de violencia cometidos contra personas por su orientación sexual e identidad de género”, A/HRC/19/41, 17 de noviembre de 2011, párrs. 71-73, disponible en: http: / / www.ohchr.org/Documents/HRBodies/ HRCouncil/RegularSession/Session19/A-HRC-19-41_sp.pdf. 
Esta revista forma parte del acervo de la Biblioteca Jurídica Virtual del Instituto de Investigaciones Jurídicas de la UNAM

faciliten el reconocimiento legal del género preferido por este colectivo y que se disponga lo necesario para rehacer los documentos de identidad, especialmente en cuanto al cambio de sexo y nombre. ${ }^{96}$

A nivel interamericano, la $\mathrm{CIDH}$ ha determinado una serie de parámetros para la protección de las personas con identidad de género diversa. ${ }^{97} \mathrm{El} \mathrm{docu-}$ mento más importante en este sentido es el informe denominado "Violencia contra personas LGBTI”, de 2015. La Comisión estableció que el misgendering ${ }^{98}$ y la utilización de pronombres y del nombre registral son formas de violencia moral. ${ }^{99}$ Asimismo, la Comisión determinó que los Estados deben aprobar leyes que reconozcan el derecho a la identidad de género de las personas sin patologizarlas, de acuerdo con el numeral 2o. de la CADH. ${ }^{100} \mathrm{Como}$ recomendación a los Estados, siguiendo las buenas prácticas de algunos países de la región, ${ }^{101}$ dispuso que se deben adoptar leyes de identidad de género que permitan rectificar el nombre y sexo de los documentos oficiales, a través de procedimientos expeditos y sencillos, preferiblemente no judiciales, sin necesidad de evaluaciones periciales, ya sean médicas o psiquiátricas. ${ }^{102}$

Como último punto en este apartado, no debe olvidarse que dichos procedimientos deberían ser gratuitos en aplicación del principio de paralelismo de las formas, según el cual "aquello creado mediante una específica forma ha de ser eliminado o variado a través del mismo mecanismo". ${ }^{103}$ Lo anterior en el entendido de que, según el Fondo de las Naciones Unidas para la Infancia, es un requisito que la inscripción de las personas sea universal y gratuita. ${ }^{104}$ Ergo, si el procedimiento de inscripción es gratuito, la

96 Ibidem, párr. 84.

97 Una de las medidas que más destacan es la creación de la Relatoría sobre derechos LGBTI.

98 Acción de utilizar el sexo designado al nacer para referirse a la persona con identidad de género diversa.

99 Ibidem, párrs. 132, 133 y 158.

100 Ibidem, párr. 419. Lo más interesante de este aspecto es que existe evidencia científica de que, en aquellos países en que se han aprobado leyes de esta guisa, la violencia contra las personas con identidad de género diversa disminuye.

101 Ibidem, párr. 420.

102 Ibidem, Recomendaciones generales, núm. 26.

103 Sala Primera, Resolución 00094-2011 de las 9:10 horas del 3 de febrero de 2011.

104 UNICEF, "El derecho a la identidad: Los registros de nacimiento en América Latina y el Caribe”, Desafíos, Santiago, núm. 11, noviembre de 2011, disponible en https: / / www. unicef. org/lac/Desafios-13-CEPAL-UNICEF.pdf. 
Esta revista forma parte del acervo de la Biblioteca Jurídica Virtual del Instituto de Investigaciones Jurídicas de la UNAM

forma para modificarlo — en todo o en parte — debe hacerse mediante los mismos requisitos y características, o cuanto menos, similares.

\section{Sobre la ADECUACión DEL ARTículo 54 DEL CÓdigo CIVIL COSTARRICENSE A LOS ESTÁNDARES INTERNACIONALES}

Procede en este punto, a partir de la batería teorética expuesta por parte de las interpretaciones jurisprudenciales, determinar si el numeral 54 del Código Civil costarricense, ${ }^{105}$ que establece el derecho al cambio de nombre y el procedimiento para ejercerlo en dicha nación, cumple o no con los presupuestos mínimos determinados por la doctrina internacional de los derechos humanos. Para ello, se explican los tres supuestos normativos del mentado artículo, a saber: 1) el registro de los costarricenses; 2) el derecho al nombre, y 3) la necesidad de una autorización de un tribunal por medio de la jurisdicción voluntaria.

\section{El registro de las personas costarricenses}

De acuerdo con la Constitución Política de Costa Rica, ${ }^{106}$ el registro de los costarricenses (sea por nacimiento o naturalización) está a cargo del Tribunal Supremo de Elecciones (en adelante, TSE). ${ }^{107}$ La oficina encargada es el Registro Civil, que lleva el Registro Central del Estado Civil.

La inscripción es realizada generalmente por los padres luego del nacimiento, ${ }^{108}$ momento en el cual se adquiere la existencia legal, ${ }^{109}$ lo cual in-

105 Dicha norma dispone expresamente: “Todo costarricense inscrito en el Registro del Estado Civil puede cambiar su nombre con autorización del Tribunal lo cual se hará por los trámites de la jurisdicción voluntaria promovidos al efecto”, Ley núm. 63, 28 de septiembre de 1887 (en adelante, Código Civil).

106 Constitución Política de la República de Costa Rica del 7 de noviembre de 1949, vigente desde el 8 de noviembre de 1949 (en adelante, Constitución Política).

107 Véase artículo 104 de la Constitución Política.

108 Véase artículo 49 de la LOTSE.

109 Cfr. Sala Constitucional de la Corte Suprema de Justicia de Costa Rica (en adelante, Sala Constitucional”). Resolución 2007-015348 de las 15:12 horas del 23 de octubre de 2007. 
Esta revista forma parte del acervo de la Biblioteca Jurídica Virtual del Instituto de Investigaciones Jurídicas de la UNAM

cide en el derecho humano a la personalidad jurídica. ${ }^{110}$ Quienes realizan la inscripción escogen el nombre de la persona. ${ }^{111}$ Éste debe estar compuesto por un nombre de pila (conformado por un máximo de dos palabras) y los apellidos del padre y de la madre, en ese orden; en caso de desconocer al padre, se le consignan los apellidos de la madre. ${ }^{112}$

Es menester indicar que existen dos procedimientos para realizar cambios en el nombre en la sede administrativa, sin necesidad de acudir a un tribunal jurisdiccional, pero únicamente para realizar rectificaciones menores.

El primero de ellos es cuando existen errores notorios y que no requieren de mayor constatación (v.g. errores ortográficos o de otro tipo en el nombre, apellidos o sexo), para corregirlos se realiza un procedimiento sencillo, en donde el registrador General — de oficio o a petición de parte- ordena la corrección por medio de una resolución y se publica en el Diario Oficial, con una anotación marginal en el asiento respectivo. ${ }^{113}$

El segundo procedimiento, se denomina "ocurso"; ${ }^{114}$ éste procede cuando el error necesita de una mayor constatación, y en él deben intervenir las personas magistradas del TSE en resolución definitiva; ${ }^{115}$ el procedimiento involucra tres publicaciones sucesivas en el Diario Oficial y las personas interesadas o afectadas pueden intervenir. ${ }^{116}$

110 Cfr. Tribunal Contencioso Administrativo (en adelante, TCA), Sección Cuarta, voto núm. 0106-2014-IV, de las 15:00 del 4 de diciembre de 2014. Confirmada por la Sala Primera. Resolución 001016-A-S1-2016 de las 16:40 horas del 6 de octubre de 2016.

111 Véase artículo 51 de la LOTSE.

112 Véase artículo 19 ejusdem.

113 Véase artículo 65 de la LOTSE.

114 Su origen etimológico es: "[c]omo bien es conocido, la palabra «ocurso» en un sentido amplio es utilizada en el ámbito jurídico para referirse al escrito presentado ante una oficina gubernamental en el ejercicio de la profesión de abogado. Deriva del latín «occursus» «encuentro», de occurrere «acudir, presentarse», de ob- «hacia, ante» + currere «correr». En síntesis hace referencia a la petición por escrito que se plantea en pos de la defensa de los derechos de un defendido o representado en una determinada relación jurídica sea esta voluntaria o no”. TCA, Sección Cuarta, voto núm. 0106-2014-IV de las 15:00 del 4 de diciembre de 2014. Confirmada por la Sala Primera. Resolución 001016-A-S1-2016 de las 16:40 horas del 6 de octubre de 2016.

115 Véase artículo 66 ejusdem.

116 De forma más detallada: "En el caso del ordenamiento jurídico nacional, la palabra se ha reservado a los procedimientos administrativos (no en vía jurisdiccional) tendientes a rectificar o modificar errores en los asientos de las bases de datos oficiales. No se trata una 
Esta revista forma parte del acervo de la Biblioteca Jurídica Virtual del Instituto de Investigaciones Jurídicas de la UNAM

De acuerdo con las interpretaciones que ha realizado el TSE, las vías administrativas de la rectificación simple o del ocurso no son las idóneas para realizar cambios en lo consignado sobre el sexo de la persona y su nombre de pila, pues en los casos en los que no se busque una simple corrección sino una significativa modificación, como lo sería en el caso de compatibilizar el nombre con la identidad de género, debería acudirse a la vía jurisdiccional. Solamente por sentencia judicial en firme que obligue al Registro Civil a modificar el asiento del nombre o del sexo se puede realizar dicho cambio. ${ }^{117}$

Es necesario indicar que en Costa Rica, como en la mayoría de países de tradición romano-germánica, los procedimientos administrativos se caracterizan por los siguientes principios generales: a) no requieren patrocinio letrado; ${ }^{118} b$ ) el impulso oficioso; ${ }^{119} c$ ) el informalismo (la forma no puede prevalecer sobre el fondo); ${ }^{120} \mathrm{~d}$ ) el in dubio pro peticione, ${ }^{121} \mathrm{y}$ e) la celeridad y la eficiencia. ${ }^{122}$

inconformidad propia de la autodeterminación informativa (que los datos no sean ciertos, que estén desactualizados, incompletos o que lesionan a grupos sensibles, entre otros). Se trata en efecto de un procedimiento sumario, normalmente ante situaciones palmarias y que constan frente a la misma Administración por lo general (ordinariamente no es necesario ni aportar prueba), de suerte que la solicitud va encaminado a corregir esa situación dentro de un asiento o registro a cargo de una autoridad estatal. En lo que al Registro Civil corresponde los ocursos pueden darse frente a asientos de nacimiento, matrimonio, defunción o naturalización. Errores en los lugares, en los días, en los años, en números de identificación, en el nombre de las personas, entre otros conceptos entran en la figura que nos ocupa; la determinación de la incongruencia en ocasiones se logra extraer del mismo asiento o la confrontación de otro, así como del documento público que hace la comunicación la que a su vez genera el registro respectivo”. TCA, Sección Cuarta, voto núm. 0106-2014-IV de las 15:00 del 4 de diciembre de 2014. Confirmada por la Sala Primera. Resolución 001016-A-S1-2016 de las 16:40 horas del 6 de octubre de 2016.

117 TSE, Acta núm. 104-2010 de las nueve horas del 11 de noviembre de 2010, artículo cuarto: Asuntos del Registro Civil, disponible en: http://www.tse.go.cr/actas/2010/1042010-del-11-de-noviembre-del-2010.html.

118 Véase artículo 220 de la Ley General de la Administración Pública, Ley núm. 6227, 2 de mayo de 1978 (en adelante, LGAP).

119 Véase artículo 222 ejusdem.

120 Véanse artículos 223 y 224 ejusdem.

121 Véase artículo 224 ejusdem.

122 Véase artículo 225 ejusdem. 
Esta revista forma parte del acervo de la Biblioteca Jurídica Virtual del Instituto de Investigaciones Jurídicas de la UNAM

\section{Derecho al nombre en Costa Rica}

Como primer punto, debe exponerse que en la literalidad de la Constitución Política costarricense no existe ninguna norma que regule el derecho al nombre de las personas, pese a ser un derecho humano internacionalmente reconocido. Ahora bien, dicho precepto puede extraerse del principio de libertad de las personas (artículos 20 y 28), de la dignidad humana (numeral 33) y del derecho a conocer quiénes son los progenitores, en cuanto al derecho a los apellidos (precepto 53). De igual forma los numerales 7 o. y 48 constitucionales incorporan al derecho interno las disposiciones del derecho internacional, en especial lo referente a los derechos humanos. ${ }^{123}$

Específicamente en la legislación interna costarricense, el derecho al nombre está consagrado en la normativa civil, la cual dispone que el nombre es parte integral de los derechos de la personalidad, se dice que "[e]l nombre es la designación oficial de una persona”. ${ }^{124}$ Éstos, por definición, son privados, absolutos, extrapatrimoniales e inherentes a la condición humana. ${ }^{125}$

123 Así interpretado por la Sala Constitucional al determinar: "Aunque el derecho al nombre no está explícitamente reconocido en nuestra Constitución Política, no cabe duda que se incorpora al elenco de derechos fundamentales que esta reconoce y tutela, por ser intrínsecamente derivado de la propia dignidad de la persona humana y por lo dispuesto en su artículo 48, ya que ha sido universalmente reconocido como tal en numerosos instrumentos internacionales, como por ejemplo, en la Convención Americana sobre Derechos Humanos". Resolución 6564-94 de las 14:18 horas del 4 de noviembre de 1994.

124 Sala Constitucional. Resolución 2011-015345 de las 14:46 horas del 9 de noviembre de 2011 .

125 ElTCA, refrendado por la Sala Primera de la Corte Suprema costarricense (en adelante, Sala Primera), dispuso que: "La doctrina ha procurado definir estos derechos estableciendo que son los que garantizan a toda persona el señorío sobre una parte de sus derechos esenciales, los que protegen al ser humano y constituye la manifestación de sus facultades físicas espirituales, los que garantizan al sujeto la protección y tutela de sus bienes jurídicos más esenciales; pero quizá la definición más completa es considerarlos como derechos subjetivos absolutos privados extrapatrimoniales que posee toda persona por ser tal y que garantizan la tutela y protección de los bienes jurídicos inmersos en el ser humano como ser la vida, la integridad física, el nombre, el domicilio, la correspondencia, etc.; de suerte que se ocupan del ser humano como unidad biológica, física y jurídica; como un ser social que vive en una comunidad y merece que se lo proteja del avasallamiento de terceros. Los derechos de la personalidad son bienes jurídicos que se caracterizan por ser privados, absolutos, extrapatrimoniales y que el ser humano no necesita adquirirlos salvo casos excepcionales, sino que son inherentes a su condición y tampoco es una concesión gratuita del legislador, sino que éste ha tomado en cuenta la naturaleza humana. Reciben también estos nombres: como derechos esenciales, innatos, personalísimos 
Esta revista forma parte del acervo de la Biblioteca Jurídica Virtual del Instituto de Investigaciones Jurídicas de la UNAM http://www.juridicas.unam.mx/ https://biblio.juridicas.unam.mx/bjv https://revistas.juridicas.unam.mx/ DOI: http://dx.doi.org/10.22201/iij.24487872e.2018.18.12102

A nivel civil, toda persona tiene la potestad del nombre, es decir, tiene el derecho y el deber-poder de contar con un nombre que la identifique. ${ }^{126}$ Esto se conoce en doctrina como la "individualización del sujeto", elemento configurador del estado civil y el principal factor de identificación, ello sin olvidar que también es una expresión de la vida moral y material de un sujeto con respecto a sus vínculos familiares y sociales. ${ }^{127}$

En cuanto al nombre, operan los principios de obligatoriedad, inmutabilidad, indivisibilidad e imprescriptibilidad. ${ }^{128}$ De especial interés son los atributos de obligatoriedad e inmutabilidad que le ha dado la jurisprudencia costarricense, al respecto ha establecido:

Es obligatorio en tanto es indispensable para que cumpla con la función de identificación e individualización de las personas... En principio, el nombre es inmutable pues de lo contrario la identificación sería difícil. Sin embargo, algunas legislaciones establecen supuestos concretos y específicos en los que se permite el cambio de nombre. Nuestro Código Civil no establece requisitos en ese sentido, solo lo prevé y otorga al Juez la facultad para autorizarlo cuando así lo estime oportuno... En nuestro país, el nombre de pila puede ser cambiado en cualquier momento, a través del procedimiento judicial correspondiente. ${ }^{129}$

Así interpretado, el nombre de pila en Costa Rica es obligatorio y no se podría, en tesis de principio, cambiar "a placer" por seguridad jurídica. Esto,

y privativos del sujeto; pero el concepto de la personalidad tiene su origen en la doctrina alemana y es la más generalizada porque empieza del concepto de Personalidad — aptitud de ser titular de derechos y deberes - Cuando hablamos de derechos de la personalidad estamos hablando de bienes jurídicos que están inmersos en esa personalidad en razón de su naturaleza. Entre las características que se le señalan están el ser originarios e innatos (no se crean), absolutos, privados, extrapatrimoniales, indisponibles, res extra comercium (intransferibles), inmodificables, irrenunciables e imprescriptibles". TCA, Sección Cuarta, voto núm. 0106-2014-IV de las 15:00 del 4 de diciembre de 2014. Confirmada por la Sala Primera. Resolución 001016-AS1-2016 de las 16:40 horas del 6 de octubre de 2016.

126 Véase artículo 49 del Código Civil. Cfr. Sala Constitucional. Resolución 2007-015348 de las 15:12 horas del 23 de octubre de 2007.

127 Pérez Vargas, Víctor, Derecho privado, 3a. ed., San José, Imprenta LIL, 1994, p. 95. Cfr. Sala Constitucional. Resolución 1999-01894 de las 10:33 horas del 12 de marzo de 1999.

128 Cfr. Sala Constitucional. Resolución 6564-94 de las 14:18 horas del 4 de noviembre de 1994.

129 Sala Constitucional. Resolución 2011-015345 de las 14:46 horas del 9 de noviembre de 2011 . 
Esta revista forma parte del acervo de la Biblioteca Jurídica Virtual del Instituto de Investigaciones Jurídicas de la UNAM

debido a que para dicho cambio debe existir un análisis de conveniencia por parte de una persona juzgadora, por medio de un proceso jurisdiccional, con las consecuencias que ello implica.

El nombre en Costa Rica se compone por el nombre de pila (nombre genérico o propio) y por los apellidos, en los que el del padre antecede al de la madre (nombre de familia o patronímico). ${ }^{130}$ En principio, no existe ninguna restricción legal para escoger el nombre, ${ }^{131}$ únicamente se establece que para la persona expósita debe seleccionarse uno que no cause burla, descrédito o que pueda exponerle al desprecio público. ${ }^{132}$ Empero, de forma interpretativa, se ha determinado que para la elección del nombre por parte de los padres, por una circunstancia de limitación basada en la dignidad, se deben aplican de manera analógica estas disposiciones. ${ }^{133}$ En esta misma línea, se ha dispuesto jurisprudencialmente que el nombre es "indicador de sexo y estado y... signo relevante de la personalidad". ${ }^{134}$

En conclusión, el nombre en Costa Rica se caracteriza por ser obligatorio, es decir, debe ser utilizado para cualquier tipo de trámite oficial y para presentarse ante la autoridad pública; asimismo es inmutable, pues únicamente por medio de un proceso jurisdiccional se puede modificar, en el cual se analiza la conveniencia del cambio. En esta línea, aunque legalmente no existe una restricción en cuanto a la elección del nombre, de forma interpretativa, los tribunales han determinado, inter alia, que el nombre debe corresponder con el sexo biológico, para evitar descrédito o burla.

\section{Autorización del cambio de nombre por medio de la jurisdicción voluntaria}

Como se indicó anteriormente, el cambio de nombre debe realizarse por medio de un proceso judicial, denominado "jurisdicción voluntaria" o "actividad procesal no contenciosa”, para contar con la autorización del Tribu-

130 Cfr. Sala Constitucional. Resolución 2007-015348 de las 15:12 horas del 23 de octubre de 2007.

131 Cfr. Sala Constitucional. Resolución 2011-015345 de las 14:46 horas del 9 de noviembre de 2011.

132 Véase artículo 51 ejusdem.

133 Cfr. Pérez Vargas, Víctor, op. cit., p. 96.

134 Sala Constitucional. Resolución 6564-94 de las 14:18 horas del 4 de noviembre de 1994. 
Esta revista forma parte del acervo de la Biblioteca Jurídica Virtual del Instituto de Investigaciones Jurídicas de la UNAM http://www.juridicas.unam.mx/ https://biblio.juridicas.unam.mx/bjv https://revistas.juridicas.unam.mx/ DOI: http://dx.doi.org/10.22201/iij.24487872e.2018.18.12102

nal, sin que la ley civil determine expresamente el órgano judicial competente. ${ }^{135}$ Este proceso se tramita en la competencia jurisdiccional civil, por especialidad por la materia. ${ }^{136}$

Por vía jurisprudencial se ha limitado el concepto "nombre" al de pila, al excluirse los apellidos. Lo anterior pese a que la ley no hace diferenciación expresa, pues se dice que es una forma de tutelar las relaciones filiales de los sujetos, para que éstas no cambien por condiciones emocionales del solicitante y por seguridad jurídica. ${ }^{137}$ En sentido similar, debe exponerse que no se ha permitido el cambio de sexo de la partida de nacimiento por falta de disposición legislativa. ${ }^{138}$

Es menester indicar que la competencia jurisdiccional civil costarricense tiene la particularidad de regirse por el principio de patrocinio letrado obligatorio, en el entendido de que todo escrito debe ser autenticado y el proceso debe ser dirigido por un abogado. ${ }^{139}$ Dichas personas deben cobrar,

135 TCA, Sección Cuarta, voto núm. 0106-2014-IV de las 15:00 del 4 de diciembre de 2014. Confirmada por la Sala Primera. Resolución 001016-A-S1-2016 de las 16:40 horas del 6 de octubre de 2016.

136 Cfr. Sala Primera de la Corte Suprema de Justicia de Costa Rica. Resolución 000272C-S1-2016 de las 16:24 horas del 15 de marzo de 2016; Sala Primera de la Corte Suprema de Justicia. Resolución 208 de las 14:15 horas del 31 de mayo de 1996.

137 Cfr. Sala Constitucional. Resolución 2007-015348 de las 15:12 horas del 23 de octubre de 2007 y Resolución 2011-015345 de las 14:46 horas del 9 de noviembre de 2011. En igual sentido, véase Tribunal Superior Civil de San José, Costa Rica. Resolución 188-E de las 8:25 horas del 18 de febrero de 1998; Tribunal Primero Civil de San José, Costa Rica. Resolución 488-R de las 8:15 horas del 14 de abril de 1999.

138 Véase Tribunal Primero Civil de San José, Costa Rica. Resolución 1076-2C de las 14:05 horas del 17 de diciembre de 2014, que en lo que interesa dice: "De acuerdo con el artículo 5 del Código Procesal Civil, las normas procesales son de orden público y, en consecuencia, de obligado acatamiento, tanto para el juez como para las partes y eventuales terceros. Los numerales 819 y siguientes del mismo cuerpo normativo, determinan el procedimiento de la actividad judicial no contenciosa, y precisan que se requiere de previsión expresa de la ley para que un asunto se tramite bajo esa vía procesal (véase canon 819 , inciso 13 , ibidem)... En esta inteligencia, lo resuelto deberá ser confirmado, pues no existe normativa de rango legal que permita tramitar como actividad judicial no contenciosa, lo relativo al cambio de género. Este Tribunal no pretende desconocer la existencia de la normativa internacional aludida, pero para implementar lo rogado es indispensable una regulación procesal a nivel legal, que permita su trámite por la vía escogida”.

139 Véase artículo 114 del Código Procesal Civil. Esta norma es supletoria en todos los procesos judiciales, salvo aquellos en los que expresamente se ha determinado su gratuidad. La Sala Constitucional costarricense ha declarado que "[e]l requisito de la autenticación tiene 
Esta revista forma parte del acervo de la Biblioteca Jurídica Virtual del Instituto de Investigaciones Jurídicas de la UNAM

so pena de acción disciplinaria, un mínimo de honorarios ${ }^{140}$ de acuerdo con una tabla preestablecida. ${ }^{141}$ Asimismo, para el caso del cambio de nombre, debe publicarse un edicto en el Diario Oficial, cuyo costo debe ser sufragado por la parte peticionaria. ${ }^{142}$

Específicamente, el proceso de jurisdicción voluntaria, en el cual no hay litigio, se caracteriza por tener una sencillez relativa. El proceso inicia por memorial del interesado, en donde se exponen las generalidades de la persona actora, junto con toda la prueba documental pertinente o la indicación precisa de dónde puede hallarse y la pretensión expresa.

Existe la posibilidad de realizar algún tipo de audiencia, generalmente para referirse a la prueba recabada; esto cobra importancia en los procesos de cambio de nombre, en vista de que se le da audiencia al Ministerio Público. ${ }^{143}$ La persona juzgadora puede ordenar prueba de oficio. Esto ha llevado a que se interprete que es necesaria la prueba sobre la buena conducta de la persona peticionaria para poder acceder al cambio de nombre, ${ }^{144}$ pese a que no existe exigencia legal en tal sentido.

como finalidad, garantizar que la parte cuente con patrocinio letrado para la defensa de sus intereses en el proceso, y la falta de tal requisito, no debe convertirse en un obstáculo procesal para el acceso a la justicia. Para que la norma en cuestión no resulte violatoria del debido proceso, es necesario que, si se va a sancionar procesalmente con denegar la gestión, se le prevenga a la parte omisa para que subsane el error”. Resolución 3495-94 de las 14:57 horas del 12 de julio de 1994.

140 A la fecha de presentación de esta investigación, el monto corresponde a aproximádamente ciento noventa y cuatro dólares estadounidenses, lo cual representa más de un tercio del salario mínimo mensual de una persona trabajadora no calificada; al respecto, véase: http: / / www.mtss. go.cr/temas-laborales/salarios/lista-salarios.html.

141 Véase artículo 9.4 de la Ley Orgánica del Colegio de Abogados y Abogadas de Costa Rica, Ley núm. 13, 28 de octubre de 1941. Ahora bien, en Costa Rica existen medios para que las personas de escasos recursos puedan entablar proceso judiciales — no penales - sin costo con patrocinio letrado, así la Ley de Consultorios Jurídicos y Trabajo Comunal, Ley núm. 4775, del 21 de junio de 1971, dispone que los estudiantes de derecho puedan dar asesoría jurídica bajo la dirección de una persona abogada debidamente colegiada, igualmente dispone la exención de tasas y gastos de cualquier índole.

142 Véanse artículo 226 y ss. del Código Procesal Civil.

143 Véase artículo 56 del Código Civil.

144 Véase: "En este caso lo que se solicita únicamente es el cambio de nombre de Julieta por el de July, lo que debe acogerse, pues no existen motivos que lo impidan, no sólo a tenor de la norma supra señalada, sino porque además deben tomarse en consideración otros aspectos de orden moral y social, los que quedaron debidamente demostrados en la prueba testimonial 
Esta revista forma parte del acervo de la Biblioteca Jurídica Virtual del Instituto de Investigaciones Jurídicas de la UNAM

Una vez listo el expediente, se cuenta con diez días hábiles para dictar la resolución correspondiente, sin necesidad de externar criterio de legalidad estricto, escogiendo la resolución que se considere más oportuna, ${ }^{145}$ lo cual da un amplio margen de discrecionalidad judicial en la aceptación o no del cambio de nombre.

La decisión de carácter definitivo es apelable, ${ }^{146}$ pero no ante las Salas de Casación, por lo que no hay control de nomofilaquia. Por lo anterior, en estos casos la persona juzgadora tiene un amplio margen de discrecionalidad para autorizar o no el cambio de nombre, ante la escasa regulación normativa; pero se ha hecho énfasis en que la autorización debe provenir de un tribunal jurisdiccional. ${ }^{147}$ Lo anterior pese a que la literalidad del artículo 54 del Código Civil simplemente indica que está permitido el cambio de nombre con "la autorización del Tribunal", el cual perfectamente se podría entender como el Tribunal Supremo de Elecciones, sin necesidad de recurrir al trámite de la jurisdicción voluntaria.

En esta misma línea, pese a que en añejos fallos se hacía alusión a que el nombre debía designarse conforme al sexo registral de la persona promovente (por motivos de "decoro y para evitar burlas"), actualmente los juzgados civiles, aplicando control de convencionalidad difuso, han interpretado que procede el cambio de nombre pese a que éste no se encuentre tradicionalmente relacionado con el sexo registral del peticionario. Al respecto véase lo dispuesto por el Tribunal Primero Civil, que por su trascendencia se transcribe:

El A-quo rechaza la solicitud de cambio de nombre en virtud de la naturaleza de la vía; esto es, la pretensión resulta extraña para un proceso no contencioso. Dice el juzgador: "El cambio de nombre de masculino a femenino o viceversa, implica una modificación total en la percepción de parte de la sociedad hacia el individuo, es claro que tal modificación excede por mucho la finalidad buscada por el legislador al establecer un proceso no contencioso de cambio de nombre". El artículo 54 del Código Civil exige la autorización de los tribunales para cambiar el nombre. En los numerales siguientes se establece el procedimiento a seguir, sin establecer

donde se señala que la gestionante es una persona de buena conducta, honrada y trabajadora”. Tribunal Primero Civil. Resolución 659-E de las 8:40 horas del 19 de mayo de 1999.

145 Véase artículo 820 ejusdem.

146 Véase artículo 822 ejusdem.

147 Sala Constitucional. Resolución 2011-015345 de las 14:46 horas del 9 de noviembre de 2011. 
Esta revista forma parte del acervo de la Biblioteca Jurídica Virtual del Instituto de Investigaciones Jurídicas de la UNAM

el legislador motivos concretos para denegar la gestión. La norma se justificaba, en sus primeros años de vigencia, en la necesidad de garantizar al ciudadano un nombre ajeno de burlas o comparaciones que atentarán con la dignidad y los derechos humanos de toda persona, quien tiene derecho a cuestionar el nombre impuesto por sus padres. La sociedad evolucionó y, hoy en día, ha quedado en el pasado esos antecedentes. Incluso, es criticable que El Estado, por medio de los jueces, mantenga esa labor fiscalizadora de la confección del nombre. Se trata de una función eminentemente administrativa. Bajo esa línea de pensamiento, salvo situaciones excepcionales, la facultad del Juzgado es verificar el cumplimiento de los requisitos legales para conceder la autorización. El yerro del Juzgado se produce porque invade un debate ajeno a este asunto; es decir, lo relativo al género y sexualidad de las personas. Las atribuciones se reducen a conceder el cambio de nombre, sin cuestionar otras esferas íntimas del promovente. ${ }^{148}$

Dicha resolución, pese a que no hace referencia directa a los estándares internacionales en la materia, constituye un elemento innovador en la jurisprudencia civil costarricense, principalmente, porque reconoce que la función jurisdiccional se limita a verificar ciertos requisitos normativos, aunado al hecho de que admite que dicha función debería ser eminentemente administrativa. Sumado a lo anterior, reconoce la evolución social en cuanto a la aceptación del cambio de nombre con respecto a la identidad de género sin que sea posible que los juzgadores utilicen argumentaciones moralistas para rechazar tales peticiones. Pese a lo anterior, se mantiene el criterio jurisprudencial de solicitar una prueba testimonial en cuanto al uso habitual del nombre y de la nueva identidad de género, ${ }^{149}$ pese a que no es un requisito, lo cual podría ser una intromisión excesiva en la vida privada de la persona peticionaria.

En suma, en Costa Rica está permitido el cambio de nombre únicamente por vía de una autorización judicial que se realiza por medio de un trámite

148 Tribunal Superior Civil. Resolución 257-M de las 7:35 horas del 24 de marzo de 2010.

149 Véanse Cerdas, Daniela, “Juez abre vía para dar nueva identidad a personas «trans»”, $L a$ Nación, San José, 1 de marzo de 2015, disponible en: http://www.nacion.com/nacional/Jueznueva-identidad-personas-trans_0_1472652785.html, y Cerdas, Daniela, "Cédula otorga una nueva identidad a hombre «trans»”, La Nación, San José, 17 de abril de 2015, disponible en: http: / / www.nacion.com/nacional/Cedula-nueva-identidad-hombre-trans_O_1482051825.html. Estos fallos no se encuentran en las bases de datos de acceso público, por haber sido dictados por juzgados de primera instancia y no haber sido apelados. 
Esta revista forma parte del acervo de la Biblioteca Jurídica Virtual del Instituto de Investigaciones Jurídicas de la UNAM

de jurisdicción voluntaria. Dicho proceso es oneroso, tardado en el tiempo $^{150}$ - por requerirse la participación de varios sujetos y audiencias - y se demanda prueba testimonial por parte de las personas juzgadoras, la cual puede interferir con la intimidad de las personas peticionarias. Dichas características no se adecuan con los estándares internacionales de derechos humanos para dichos procesos, como se indicó en el apartado precedente. Como punto positivo, en dicho país no se requieren de pruebas médicas o psiquiátricas para demostrar la identidad de género profunda, lo cual va en consonancia con la despatologización de las identidades de género diversas.

\section{CONCLUSIONES GENERALES}

La identidad de género debe ser reconocida como un derecho autónomo derivable del derecho a la vida privada protegido en el artículo 11 de la $\mathrm{CADH}$. Una interpretación evolutiva de dicho numeral permite incluir dentro de su esfera de protección al derecho a la identidad de género. El reconocimiento de la misma conduce indefectiblemente a la protección del cambio de nombre de las personas conforme a su identidad de género.

Asimismo, una interpretación evolutiva y armónica de los artículos 1.1 y 18 de la CADH protege el cambio de nombre señalado. Ergo, los Estados no pueden negar, con base en ningún motivo, el nombre que cada persona seleccione para sí misma; en especial, cuando la reasignación del nombre corresponda a la identidad de género. Tal negación, al tener sustento en la identidad de género, sería evidentemente discriminatoria. Lo anterior, desde el punto de vista de las obligaciones de no-hacer (negativas) para los Estados. Empero, éstos también están obligados a realizar acciones positivas para eliminar toda forma de discriminación en contra de las personas con identidad de género diversa.

En conclusión, al interior de los ordenamientos jurídicos estatales debe reconocerse el derecho al cambio de nombre por medio de un procedimiento — preferiblemente en una sede no judicial— expedito, transpa-

150 Por ejemplo, puede verse la sentencia 2010-17807 de las 15:59 horas del 26 de octubre de 2010 de la Sala Constitucional de la Corte Suprema de Justicia de Costa Rica, en la cual declara con lugar un amparo por dilación excesiva en los trámites de un proceso de esta guisa. 
Esta revista forma parte del acervo de la Biblioteca Jurídica Virtual del Instituto de Investigaciones Jurídicas de la UNAM

rente, sencillo, que no implique ni intervenciones médicas ni dictámenes periciales psiquiátricos. ${ }^{151}$

Aunado a lo anterior, en vista de que los Estados están obligados a eliminar cualquier barrera normativa o material para el disfrute de los derechos humanos, dicho procedimiento no debería ser oneroso, lo recomendable es su gratuidad. Lo anterior por aplicación del principio de paralelismo de las formas, pues, al ser la inscripción del nacimiento universal y gratuita, su cambio debería cumplir con los mismos requisitos. Si se interpreta de forma diferente, se crearían discriminaciones odiosas entre quienes puedan costear económicamente el procedimiento y quienes no tengan los medios para ello, lo cual constituiría un trato discriminatorio, de acuerdo con el test establecido por la Corte IDH. ${ }^{152}$

Específicamente en el caso costarricense, el cambio de nombre únicamente se puede realizar por vía de una autorización judicial, por medio de un trámite de jurisdicción voluntaria. Esto en vista de que el procedimiento administrativo del ocurso está reservado solamente para corrección de errores, no para cambios totales. El proceso jurisdiccional se caracteriza por ser oneroso, tardado en el tiempo, con la participación de varios sujetos y la realización de diversas audiencias, con la evacuación de una prueba testimonial, que puede interferir con la intimidad de las personas peticionarias.

Por lo anterior, la normativa costarricense en lo referente al proceso de cambio de nombre - de la forma que ha sido interpretada - no es compatible con los estándares internacionales de derechos humanos. Ello debido a que para acceder a éste se debe acudir a un proceso judicial tardado, oneroso, que implica la presentación de una prueba testimonial que resulta invasiva en la vida privada de las personas peticionarias y que - a fin de cuentas - se encuentra en un amplio margen de apreciación por parte de la persona juzgadora, que podría utilizar argumentaciones discriminatorias para negar el cambio de nombre de acuerdo con la identidad de género. Todo ello sin posibilidad de control de nomofilaquia por parte de las Salas

151 Dichas condiciones no son parte del margen de apreciación interno de los Estados, al ser preceptos que delinean las características mínimas que deben tener los procedimientos para el cambio o rectificación de nombre de las personas con identidad de género diversa.

152 Dicho test se compone de: a) si las normas establecen una diferencia de trato; $b$ ) si esa diferencia de trato se refiere a categorías protegidas por el artículo 1.1 de la CADH, y c) si esa diferencia de trato reviste de un carácter discriminatorio. Cfr. Corte Interamericana de Derechos Humanos, Caso Flor..., cit., párr. 114 y Caso Duque..., cit., párr. 106. 
Esta revista forma parte del acervo de la Biblioteca Jurídica Virtual del Instituto de Investigaciones Jurídicas de la UNAM

de Casación. Aunado a lo anterior, la legislación y la jurisprudencia no admiten el cambio de sexo registral, bajo la excusa de "inexistencia de norma escrita". ${ }^{153}$

Empero, si se analiza la literalidad del artículo 54 del Código Civil costarricense, al referirse a "Tribunal", perfectamente podría hacer una interpretación conforme a los estándares internacionales y se podría entender que se hace referencia al mismo TSE (como superior jerárquico del Registro Civil).

Por ello, es perfectamente viable que se otorgue la autorización en vía administrativa, por medio de un ocurso, sin que afecte el orden público costarricense, con aplicación supletoria de la reglas del procedimiento administrativo.

Realizar una interpretación como la propuesta permitiría que el cambio del nombre registral se realice en una sede administrativa, lo cual implicaría la aplicación de los principios del proceso administrativo; a saber, gratuidad, impulso de oficio, informalismo, celeridad y eficiencia. Dichas características sí son compatibles con los requisitos establecidos para dichos procedimientos en la doctrina internacional de los derechos humanos.

\section{BIBLIOGRAFÍA}

Amnistía InTERnaCIONAL, El Estado decide quién soy. Falta de reconocimiento legal de la identidad de género de las personas transgénero en Europa, 2014. BAISLEY, Elizabeth, "Reaching the Tipping Point? Emerging International Human Rights Norms Pertaining to Sexual Orientation and Gender Identity", Human Rights Quarterly, Estados Unidos, vol. 38, núm. 1, febrero de 2016. Código Civil para el Distrito Federal, Asamblea Legislativa del Distrito Federal, 5 de febrero de 2015, disponible en: http://www.aldf.gob.mx/ archivo-c9dc6843e50163a0d2628615e069b140.pdf (fecha de consulta: 20 de enero de 2017).

153 Pese a ello, el TSE ha dispuesto una política institucional de no discriminación por orientación sexual e identidad de género; véase: Acta núm. 37-2016 de las diez horas del 28 de abril de 2016, sección C), disponible en: http://www.tse.go.cr/actas/2016/37-2016-del28-de-abril-de-2016.html. 
Esta revista forma parte del acervo de la Biblioteca Jurídica Virtual del Instituto de Investigaciones Jurídicas de la UNAM

Comisión InTERAmericana de Derechos Humanos, Violencia contra personas lesbianas, gay, bisexuales, trans e intersex en América, Organización de los Estados Americanos, 2015.

COMmissioner fOR Human Rights, "Human Rights and Gender Identity", Estrasburgo, 2009, pp. 7 y 8, disponible en: https://rm.coe.int/Co ERMPublicCommonSearchServices / DisplayDCTMContent? documentId=09000016806da753 (fecha de consulta: 10 de febrero de 2017).

Consejo de Derechos Humanos, Informe del Alto Comisionado de LaS NaCiOnes Unidas para los Derechos Humanos, "Leyes y prácticas discriminatorias y actos de violencia cometidos contra personas por su orientación sexual e identidad de género", A/HRC/19/41, 17 de noviembre de 2011, disponible en: http://www.ohchr.org/Documents/HRBodies / HRCouncil/RegularSession/Session19/A-HRC-19-41_sp.pdf.

Convenio del Consejo de Europa sobre prevención y lucha contra la violencia contra las mujeres y la violencia doméstica, 11 de mayo de 2011, disponible en: https://rm.coe.int/CoERMPublicCommonSearchServices/DisplayDCTMContent?documentId $=0900001680462543$ (fecha de consulta: 20 de enero de 2017).

Convenio Europeo de Derechos Humanos, Consejo de Europa, 4 de noviembre de 1950, disponible en: http://www.echr.coe.int/documents/ convention_spa.pdf.

Decreto 1227, Ministerio de Justicia y el Derecho de la República de Colombia, 4 de junio de 2015, disponible en: https://www. minjusticia.gov. co/Portals / / / Ministerio / decreto\%20unico /\%23\%20decretos / 1.\%20DECRETO\%202015-1227\%20sexo\%20cédula.pdf (fecha de consulta: 20 de enero de 2017).

Del Toro Huerta, Mauricio Iván, "El fenómeno del soft law y las nuevas perspectivas del derecho internacional", Anuario Mexicano de Derecho Internacional, vol. 6, 2006, disponible en: https://revistas.juridicas.unam. $\mathrm{mx} /$ index.php/derecho-internacional/article/view/160/257\#N50.

ESPINOSA PÉREZ, Beatriz, "Cuerpos e identidades. El transexualismo reta al derecho", en ESPINOSA PÉREZ, Beatriz (ed.), Cuerpos y diversidad sexual: aportes para la igualdad y el reconocimiento, Bogotá, Pontificia Universidad Javeriana, 2008.

GAUCHÉ, Ximena, "Derecho, derechos humanos y diversidad sexual" en ERAZO, Ximena et al. (eds.), Derechos humanos, diversidad sexual y politicas públicas en América Latina, Chile, LOM Ediciones-Fundación Henry Dunant, 2015. 
Esta revista forma parte del acervo de la Biblioteca Jurídica Virtual del Instituto de Investigaciones Jurídicas de la UNAM

GRIGOLO, Michele, "Sexualities and the ECHR: Introducing the Universal Sexual Legal Subject”, European Journal of International Law, vol. 14, núm. 5, 2003.

Hammaberg, Thomas, Derechos humanos e identidad de género, Berlín, TransInterQueer e.V., 2010.

HAmzić, Vanja, "The Case of «Queer Muslims»: Sexual Orientation and Gender Identity in International Human Rights Law and Muslim Legal and Social Ethos", Human Rights Law Review, vol. 11, núm. 2, 2011.

HogG, Martin, "Attitudes to Sexual Identity and Practice: The Impact of Human Rights Law in the Scottish Courts", en Boyle, Alan et al. (eds.), Human Rights and Scots Law, Oxford y Oregon, Hart Publishing, 2002.

JingChun, Cao, "Protecting the Right to Privacy in China", Victoria University of Wellington Law Review, vol. 36, núm. 3, 2005, disponible en: https: / /www.victoria.ac.nz/law/research/publications/vuwlr/prev-issues/vol-36-3/jingchun.pdf.

Ley núm. 26.743, Senado y Cámara de Diputados de la Nación Argentina, 9 de mayo de 2012, disponible en: http: //www.tgeu.org/sites/default/files/ ley_26743.pdf (fecha de consulta: 25 de enero de 2017).

Ley núm. 40, Ley Orgánica de Gestión de la Identidad y Datos Civiles, Asamblea Nacional de la República del Ecuador, 4 de febrero de 2016, disponible en: http://www.asambleanacional.gob.ec/es/system/files/ro_ ley_organica_de_gestion_de_la_identidad_y_datos_civiles_ro_684_2do_ supl_04-02-2015.pdf (fecha de consulta: 20 de enero de 2017).

Ley núm. 807, Ley de Identidad de Género, Asamblea Legislativa Plurinacional del Estado Plurinacional de Bolivia, 21 de mayo de 2016, disponible en: http: / / www.derechoteca.com/gacetabolivia/ley-no-807-del-21-demayo-de-2016 (fecha de consulta: 20 de enero de 2017).

Ley núm. 18620, Ley de derecho a la identidad de género y al cambio de nombre y sexo en documentos identificatorios, Senado y Cámara de Representantes de la República Oriental del Uruguay, 25 de octubre de 2009, disponible en: https://legislativo.parlamento.gub.uy/temporales/ leytemp4059060.htm (fecha de consulta: 20 de enero de 2017).

MCGOLDRICK, Dominic, "The Development and Status of Sexual Orientation Discrimination under International Human Rights Law", Human Rights Law Review, vol. 16, núm. 4, 2016.

O’Flaherty, Michael y FISHER, John, "Sexual Orientation, Gender Identity and International Human Rights Law: Contextualising the Yogyakarta Principles", Human Rights Law Review, vol. 8, núm. 2, 2008. 
Esta revista forma parte del acervo de la Biblioteca Jurídica Virtual del Instituto de Investigaciones Jurídicas de la UNAM

PÉReZ Vargas, Víctor, Derecho privado, 3a. ed., San José, Imprenta LIL, 1994.

Principios deYogyakarta sobre la aplicación de la legislación internacional de derechos humanos en relación con la orientación sexual y la identidad de género, Panel Internacional de Especialistas en Legislación Internacional de Derechos Humanos y en Orientación Sexual e Identidad de Género, marzo de 2007, disponible en: http: //www.refworld.org/cgi-bin/texis / $v t x / \mathrm{rwmain} /$ opendocpdf.pdf?reldoc $=y$ \&docid $=48244 \mathrm{e} 9 f 2$.

Recomendación 1117/1989, Parliamentary Assembly of Council of Europe, 29 de septiembre de 1989, disponible en: http://assembly.coe.int / $n_{W} / \mathrm{xml} /$ XRef/Xref-XML2HTML-en.asp?fileid=15151\&lang=en_ffecha de consulta: 1 de febrero de 2017).

REDLACTRAns, "Informe sobre el acceso a los derechos económicos, sociales y culturales de la población trans en Latinoamérica y el Caribe”, 2014, disponible en: http://redlactrans.org.ar/site/wp-content/uploads/2015/03/In forme\%20DESC\%20trans.pdf.

Resolución AG/RES. 2435 (XXXVIII-O/08), Asamblea General de la OEA, 3 de junio de 2008, disponible en: http: / /www.oas.org/es/sla/ddi / docs/AG-RES_2435_XXXVIII-O-08.pdf (fecha de consulta: 14 de enero de 2017).

Resolución AG/RES. 2504 (XXXIX-O/09), Asamblea General de la OEA, 4 de junio de 2009, disponible en: http: / / www.oas.org/es/sla/ddi / docs/AGRES_2504_XXXIX-O-09.pdf (fecha de consulta: 14 de enero de 2017).

Resolución AG/RES. 2600 (XL-O/10), Asamblea General de la OEA, 8 de junio de 2010, disponible en: http: / / www.oas.org/es/sla/ddi / docs/AGRES_2600_XL-O-10_esp.pdf (fecha de consulta: 14 de enero de 2017).

Resolución AG/RES. 2653 (XLI-0/11), Asamblea General de la OEA, 7 de junio de 2011, disponible en: http://www.oas.org/es/sla/ddi/docs/ AG-RES_2653_XLI-O-11_esp.pdf (fecha de consulta: 14 de enero de 2017).

Resolución AG/RES. 2721 (XLII-O/12), Asamblea General de la OEA, 4 de junio de 2012, disponible en: http://www.oas.org/es/sla/ddi/docs / AG-RES_2721_XLII-O-12_esp.pdf (fecha de consulta: 14 de enero de 2017).

Resolución AG/RES. 2807 (XLIII-O/13), Asamblea General de la OEA, 6 de junio de 2013, disponible en: http: / /www.oas.org/es/sla/ddi /docs / AG-RES_2807_XLIII-O-13.pdf_(fecha de consulta: 14 de enero de 2017). 
Esta revista forma parte del acervo de la Biblioteca Jurídica Virtual del Instituto de Investigaciones Jurídicas de la UNAM

Resolución A/HRC/RES/17/19, Consejo de Derechos Humanos, 14 de julio de 2011, disponible en: https: / /documents-dds-ny.un.org/doc/UNDOC/ GEN/G11/148/76/PDF/G1114876.pdf?OpenElement (fecha de consulta: 1 de febrero de 2017).

Resolución A/HRC/RES/32/2, Consejo de Derechos Humanos, 15 de julio de 2016, disponible en: http://www.un.org/en/ga/search/view_doc.asp?symbol=A/HRC/RES/32/2 (fecha de consulta: 1 de febrero de 2017).

Rudolf, Beate, "European Court of Human Rights: Legal status of postoperative transsexuals", International Journal of Constitutional Law, vol. 1, núm. 4, 2003,

SHAw, Malcolm, International Law, 5a. ed., Reino Unido, Cambridge University Press, 2003,

Solove, Daniel, "Conceptualizing Privacy", California Law Review, vol. 90, núm. 4, 2002, disponible en: http://scholarship.law.berkeley.edu/cgi/ viewcontent.cgi? article $=1408$ \&context $=$ californialawreview .

Theilen, Jens, "Depathologisation of Transgenderism and International Human Rights Law”, Human Rights Law Review, vol. 14, núm. 2, 2014.

UNICEF, "El derecho a la identidad: Los registros de nacimiento en América Latina y el Caribe”, Desafíos, Santiago, núm. 11, noviembre de 2011, disponible en https: / / www.unicef.org/lac/Desafios-13-CEPAL-UNICEF.pdf.

Vital Statistics Act, 29 de mayo de 2014, Columbia Británica, Canadá, disponible en: http://canlii.ca/t/5297t (fecha de consulta: 21 de enero de 2017).

Vital Statistics Act, 10 de noviembre de 2016, Manitoba, Canadá, disponible en: http: / / canlii.ca/t/52tvp_(fecha de consulta: 21 de enero de 2017).

\section{Legislación costarricense}

Código Civil de la República de Costa Rica, 28 de setiembre de 1887.

Constitución Política de la República de Costa Rica, 7 de noviembre de 1949.

Decreto Ejecutivo 39078, Decreto Ejecutivo de Arancel de honorarios por servicios profesionales de abogacía y notariado (Honorarios de Abogados, Abogadas y Notarios), 25 de mayo de 2015.

Ley de la República de Costa Rica núm. 3504, 10 de mayo de 1965.

Ley 13, Ley Orgánica del Colegio de Abogados y Abogadas de Costa Rica, 28 de octubre de 1941. 
Esta revista forma parte del acervo de la Biblioteca Jurídica Virtual del Instituto de Investigaciones Jurídicas de la UNAM

Ley núm. 6227, Ley General de la Administración Pública de la República de Costa Rica, 2 de mayo de 1978.

Ley núm. 7130, Código Procesal Civil de la República de Costa Rica, 16 de agosto de 1989.

Ley núm. 9342, Código Procesal Civil de la República de Costa Rica, 3 de febrero de 2016.

Reglamento del Registro del Estado Civil, Reglamento del Tribunal Supremo de Elecciones núm. 06-2011.

Reglamento de la cédula de identidad con nuevas características, Reglamento del TSE núm. 9-2016.

Tribunal Supremo De Elecciones, Acta núm. 104-2010 de las nueve horas del 11 de noviembre de 2010, artículo Cuarto: Asuntos del Registro Civil, disponible en: http://www.tse.go.cr/actas/2010/104-2010-del-11de-noviembre-del-2010.html.

Tribunal Supremo de Elecciones, Acta núm. 37-2016 de las diez horas del 28 de abril de 2016, sección C), disponible en: http: / /www.tse.go.cr/ actas/2016/37-2016-del-28-de-abril-de-2016.html.

\section{Casos citados}

Corte Interamericana De Derechos Humanos, Caso Atala Riffo y niñas vs. Chile, Fondo, reparaciones y costas. Sentencia del 24 de febrero de 2012, Serie C 239.

Corte Interamericana De Derechos Humanos, Caso Duque vs. Colombia, Excepciones preliminares, Fondo, reparaciones y costas. Sentencia del 26 de febrero de 2016, Serie C 310.

Corte Interamericana de Derechos Humanos, Caso Flor Freire vs. Ecuador, Excepción preliminar, Fondo, reparaciones y costas. Sentencia del 31 de agosto de 2016, Serie C 315.

Corte Interamericana de Derechos Humanos, Caso Gelman vs. Uruguay, Fondo y reparaciones. Sentencia del 24 de febrero de 2011, Serie C. 221. Corte Interamericana de Derechos Humanos, Caso las niñas Yean y Bosico vs. República Dominicana. Sentencia del 8 de septiembre de 2005, Serie C 130.

Corte Interamericana de Derechos Humanos, Caso Personas dominicanas y haitianas expulsadas vs. República Dominicana, Excepciones preliminares, Fondo, reparaciones y costas. Sentencia del 28 de agosto de 2014, Serie C 282. 
Esta revista forma parte del acervo de la Biblioteca Jurídica Virtual del Instituto de Investigaciones Jurídicas de la UNAM

Corte Interamericana de Derechos Humanos, Condición Jurídica y Derechos Humanos del Niño, Opinión Consultiva OC-17/2002, 28 de agosto de 2002. Serie A 17.

Sala Constitucional de la Corte Suprema de Justicia, Costa Rica, Resolución 3495-94 de las 14:57 horas del 12 de julio de 1994.

Sala Constitucional de la Corte Suprema de Justicia, Costa Rica, Resolución 6564-94 de las 14:18 horas del 4 de noviembre de 1994.

Sala Constitucional de la Corte Suprema de Justicia, Costa Rica, Resolución 1999-01894 de las 10:33 horas del 12 de marzo de 1999.

Sala Constitucional de la Corte Suprema de Justicia, Costa Rica, Resolución 2007-015348 de las 15:12 horas del 23 de octubre de 2007.

Sala Constitucional de la Corte Suprema de Justicia, Costa Rica, Resolución 2011-015345 de las 14:46 horas del 9 de noviembre de 2011.

Sala Constitucional de la Corte Suprema de Justicia, Costa Rica, Resolución 001016-A-S1-2016 de las 16:40 horas del 6 de octubre de 2016.

Sala Primera de la Corte Suprema de Justicia, Costa Rica, Resolución 000272-C-S1-2016 de las 16:24 horas del 15 de marzo de 2016.

Tribunal Contencioso Administrativo costarricense, Sección Cuarta, Resolución 0106-2014-IV de las 15:00 del 4 de diciembre de 2014.

Tribunal Europeo de Derechos Humanos, Caso B vs. Francia. Sentencia del 25 de marzo de 1992, Solicitud número 13343/87.

Tribunal Europeo de Derechos Humanos, Caso Christine Goodwin vs. Reino Unido. Sentencia del 11 de julio de 2002, Solicitud número 28957/95.

Tribunal Europeo de Derechos Humanos, Caso I. vs. Reino Unido. Sentencia del 11 de julio de 2002, Solicitud número 25680/94.

Tribunal Europeo de Derechos Humanos, Gran Cámara, Caso Hamalainan vs. Finlandia. Sentencia del 16 de julio de 2014, Solicitud número 37359/09.

Tribunal Europeo de Derechos Humanos, Sección Cuarta, Caso Grant vs. Reino Unido. Sentencia del 23 de mayo de 2006, Solicitud número 32570/03.

Tribunal Primero Civil de San José, Costa Rica, Resolución 1076-2C de las 14:05 horas del 17 de diciembre de 2014. 